\title{
Investigations into a putative role for the novel BRASSIKIN pseudokinases in compatible pollen-stigma interactions in Arabidopsis thaliana
}

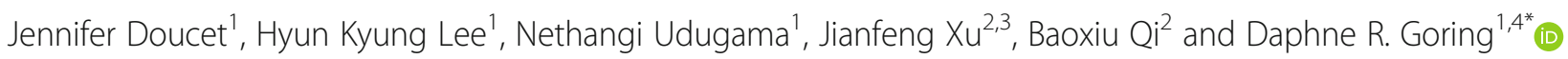

\begin{abstract}
Background: In the Brassicaceae, the early stages of compatible pollen-stigma interactions are tightly controlled with early checkpoints regulating pollen adhesion, hydration and germination, and pollen tube entry into the stigmatic surface. However, the early signalling events in the stigma which trigger these compatible interactions remain unknown.

Results: A set of stigma-expressed pseudokinase genes, termed BRASSIKINs (BKNs), were identified and found to be present in only core Brassicaceae genomes. In Arabidopsis thaliana Col-0, BKN1 displayed stigma-specific expression while the BKN2 gene was expressed in other tissues as well. CRISPR deletion mutations were generated for the two tandemly linked BKNs, and very mild hydration defects were observed for wild-type Col-0 pollen when placed on the bkn1/2 mutant stigmas. In further analyses, the predominant transcript for the stigma-specific BKN1 was found to have a premature stop codon in the Col-0 ecotype, but a survey of the 1001 Arabidopsis genomes uncovered three ecotypes that encoded a full-length BKN1 protein. Furthermore, phylogenetic analyses identified intact BKN1 orthologues in the closely related outcrossing Arabidopsis species, A. lyrata and A. halleri. Finally, the BKN pseudokinases were found to be plasmamembrane localized through the dual lipid modification of myristoylation and palmitoylation, and this localization would be consistent with a role in signaling complexes.
\end{abstract}

Conclusion: In this study, we have characterized the novel Brassicaceae-specific family of BKN pseudokinase genes, and examined the function of BKN1 and BKN2 in the context of pollen-stigma interactions in $A$. thaliana Col-0. Additionally, premature stop codons were identified in the predicted stigma specific BKN1 gene in a number of the $1001 \mathrm{~A}$. thaliana ecotype genomes, and this was in contrast to the out-crossing Arabidopsis species which carried intact copies of BKN1. Thus, understanding the function of BKN1 in other Brassicaceae species will be a key direction for future studies.

Keywords: Compatible pollen, Stigma, Signaling, Pseudokinase, Receptor-like cytoplasmic kinase, Brassicaceae

\footnotetext{
* Correspondence: d.goring@utoronto.ca

'Department of Cell \& Systems Biology, University of Toronto, Toronto M5S

3B2, Canada

${ }^{4}$ Centre for the Analysis of Genome Evolution \& Function, University of

Toronto, Toronto M5S 3B2, Canada

Full list of author information is available at the end of the article
}

(c) The Author(s). 2019 Open Access This article is distributed under the terms of the Creative Commons Attribution 4.0 International License (http://creativecommons.org/licenses/by/4.0/), which permits unrestricted use, distribution, and reproduction in any medium, provided you give appropriate credit to the original author(s) and the source, provide a link to the Creative Commons license, and indicate if changes were made. The Creative Commons Public Domain Dedication waiver (http://creativecommons.org/publicdomain/zero/1.0/) applies to the data made available in this article, unless otherwise stated. 


\section{Background}

In the Brassicaceae, the early post-pollination stages of pollen adhesion and hydration, and pollen tube entry into the stigma are highly-regulated and represent the first of several stages leading to the release of the sperm cells at the ovule for fertilization (reviewed in [1-5]). The characteristic Brassicaceae "dry stigmas" lack surface secretions to facilitate pollen hydration and germination; thus, pollen recognition is required for the stigma to be receptive $[6,7]$. The Brassicaceae stigma surface is covered with unicellular stigmatic papillae, and the process of pollen capture is very rapid, occurring in as little as $30 \mathrm{~s}$ following a compatible pollination in Arabidopsis thaliana [8]. Following this, the pollen coat and stigma surface components mix to form a "pollen foot" at the location of the pollen-papillar contact, and this contributes to the process of pollen adhesion [9]. The next checkpoint of pollen acceptance is pollen hydration, where the desiccated pollen grain takes up water released by the stigmatic papilla to become metabolically active [6, 10-12].

Despite being a critical step leading to successful fertilization, the cell-cell communication events that facilitate early pollen-stigma interactions are poorly understood. There are proteins in the pollen coat that are required for pollen hydration such as the A. thaliana GRP17 oleosin-domain protein, the EXL4 extracellular lipase, and the Pollen Coat Protein-B family (PCP-B) [13-15]. The PCP-Bs are particularly interesting as they are small cysteine-rich proteins that represent promising compatible pollen recognition factors for unknown stigma receptors. A. thaliana $p c p-b \alpha / \beta / \gamma$ triple mutants displayed impaired pollen hydration and delayed pollen tube growth on wild-type stigmas [15]. Perception of peptide ligands by receptor kinases plays a prominent role in the regulation of downstream compatible pollenpistil interactions and pollen tube guidance, as well as the rejection of self-pollen in self-incompatible Brassicaceae species (reviewed in $[1,2,4,5,16]$ ).

Other factors identified on the pollen side for these early post-pollination stages are connected to the production of reactive oxygen species (ROS). Pollen NADPH oxidases were shown to be important for $\mathrm{Ca}^{2+}$ dependent ROS production in the apoplast for A. thaliana pollen tube elongation into the stigmatic papillar cell wall $[17,18]$. ROS production was again implicated in A. thaliana T-DNA insertion mutants disrupting the $\beta$ and $\gamma$ subunits of the SNF1-related protein kinase 1 complex. Mutant kin $\beta \gamma$ pollen grains displayed reduced ROS levels as a result of mitochondrial and peroxisomal defects, and this was associated with reduced hydration and germination on wild-type stigmas [19]. Finally, the SHAKER POLLEN INWARD $K^{+}$channel (SPIK) gene was found to be downregulated in $k i n \beta \gamma$ mutant pollen, and spik mutant pollen grains also displayed reduced hydration on wild-type stigmas [20].

On the stigmatic papillar side, ultrastructural studies of the pollen-papillar interface previously implicated both secretory activity and vacuolar expansion in the stigmatic papillae of Brassica and Arabidopsis species [21-25]. This exocyst complex, a vesicle-tethering complex composed of eight different subunits (SEC3, SEC5, SEC6, SEC8, SEC10, SEC15, EXO70 and EXO84), was implicated in mediating this secretory activity in the stigma [26-28]. Through the use of knockout mutants and stigma-specific RNA silencing constructs, all eight subunits were found to be required in the stigma for the compatible pollen acceptance. Wild-type pollen applied to stigmas from the exocyst subunit knockdown/knockout mutants displayed reduced pollen hydration and germination, and showed signs of disrupted secretion [22, 26, 27, 29, 30]. Other cellular responses in Brassica and Arabidopsis stigmatic papillae have also been connected to vesicle trafficking (reviewed in [31]). For example, Brassica compatible pollinations were associated with actin reorganization in the stigmatic papilla towards the pollen attachment site and microtubule depolymerization [25, 32]. Recently, another vesicle trafficking-related component, Brassica phospholipase D 1 , has been shown to be required in the stigma for compatible pollinations [33]. As well, changes in $\mathrm{Ca}^{2+}$ dynamics were observed, with small $\mathrm{Ca}^{2+}$ increases at the site of pollen attachment in $A$. thaliana stigmatic papillae [34]. Through transcriptome analyses of $A$. thaliana stigmas pre- and post-pollination, the ACA13 $\mathrm{Ca}^{2+}$ ATPase was identified as a stigmatic component and proposed to secrete $\mathrm{Ca}^{2+}$ for the developing pollen tube [35]. Finally, we have recently identified the secreted Arabidopsis E6like 1 protein as a potential structural component of the stigmatic papillae required for these early post-pollination stages [36].

While the PCP-Bs represent potential pollen ligands for compatible pollen recognition, the corresponding recognition system in the stigma is unknown. The process of pollen acceptance by the stigma is thought to be conserved in the Brassicaceae since pollen from several Brassicaceae species were able to hydrate and germinate on Arabidopsis stigmas whereas pollen from nonBrassicaceae species failed to hydrate [37]. Moreover, when pollen from various species were applied to $A$. thaliana or $B$. oleracea stigmas, there was some specificity at the pollen adhesion stage $[8,38]$. Thus in this reversegenetics study, we utilized publicly available transcriptome datasets to search for potential signalling genes that display stigma-enriched expression and were conserved within the Brassicaceae. Through this approach, we identified a novel group of Brassicaceae-specific pseudokinase genes which we termed the BRASSIKINs (BKNs). 


\section{Results}

$B K N$ s are stigma-expressed receptor-like cytoplasmic kinases

To identifying candidate stigma signalling genes, we used the expression angler tool from the Bio-Analytic Resource for Plant Biology [39]. For this search, we used the stigma-specific SLR1 gene [40] as a bait to identify other genes with similar expression patterns across the A. thaliana developmental series microarray datasets [36, 41, 42]. The gene, At5g11400, was a top hit (Additional file 2: Table S1) and displayed stigma-specific expression in the transcriptome datasets (Additional file 1: Figure S1, [35, 43, 44]). This gene is predicted to encode a novel receptor-like cytoplasmic kinase (RLCK) which we named BRASSIKIN 1 (BKN1). Interestingly, adjacent to the $B K N 1$ gene is a tandemly linked paralogue, At5g11410, named BKN2 in the A. thaliana genome (Fig. 1a). BKN2 was ranked 64th in the expression angler dataset (Additional file 2: Table S1), with expression in a wider range of tissues (Additional file 1: Figure S1). Both $B K N$ genes are also predicted to encode pseudokinases (discussed below) [46, 47].

The expression patterns for BKN1 and BKN2 were examined by RT-PCR on RNA extracted from $A$. thaliana stigmas (top $1 / 2$ pistil), ovaries (bottom $1 / 2$ pistil), leaves and roots. Both BKN1 and BKN2 were expressed in the stigma samples, with some expression for $B K N 2$ in ovary samples (Fig. 1b). The BKN1 and BKN2 expression patterns were also examined in promoter-GUS transgenic plants (promoter regions are indicated by arrows, Fig. 1a). For the transgenic BKN1p:GUS A. thaliana lines, stained inflorescences showed high levels of GUS activity in stigmas from flowers across developmental stages, but not in the other tissues in the inflorescences or in seedlings (Fig. 1c-e). The transgenic BKN2p:GUS inflorescences displayed GUS activity primarily in the flower abscission zones and in the stems (Fig. 1f-g). There was also GUS activity in some BKN2p:GUS seedlings at the leaf edges and petiole (Fig. 1h). GUS activity was not observed in BKN2p:GUS stigma tissues; however, this may be due to $B K N 2$ having much lower expression in the stigmas that may be undetectable by GUS staining (Additional file 1: Figure S1). Alternatively, the adjacent stigma specific $B K N 1$ promoter or other unknown regulatory regions may be responsible for the $B K N 2$ expression detected in the stigma tissues (Fig. 1a,b).

\section{Analysis of compatible pollen responses for $B K N 1$ and $B K N 2$ single and double knockout mutants in $A$. thaliana} Given BKN1's stigma-specific expression, we investigated whether $B K N 1$ was required for compatible pollinations by examining loss-of function mutants. A knockout line with a T-DNA inserted in the fifth exon of BKN1 was assessed for post-pollination responses (bkn1-1; Additional file 1: Figure S2a, b). The $b k n 1-1$ mutant plants did not display any discernible developmental defects and appeared fully fertile with wild-type siliques. Furthermore, pollinated $b k n 1-1$ pistils stained with aniline blue were similar to wild-type for adhered pollen grains and pollen tube growth (Additional file 1: Figure S2c, d). Given that this mutant displayed some expression upstream of the T-DNA insertion, additional BKN1 mutants were generated using a CRISPR/Cas9 genome editing system [48]. Furthermore, a similar approach was taken for BKN2 since it could potentially function redundantly to BKN1. Single deletion mutants were generated resulting in two new independent homozygous mutants for each BKN1 and BKN2: bkn1-2 and $b k n 1-3$, and $b k n 2-1$ and $b k n 2-2$ (Fig. 2a).

Similar to $b k n 1-1$, all four CRISPR deletion mutants $b k n 1-2, b k n 1-3, b k n 2-1$ and $b k n 2-2$ displayed wild-type pollen tube growth in aniline blue stained pistils that had been manually pollinated with wild-type Col-0 pollen (Fig. 3a-e). There were no discernable phenotypes at this stage for individual $b k n 1$ and $b k n 2$ loss-of-function mutants. These mutants also did not show any observable defects in the number of pollen grains adhered to the stigma or seed set, relative to Col-0 (Fig. 3f-g). We then examined one of the earliest post-compatible pollination stages, pollen hydration, which is dependent on water release from the stigma $[6,26,27]$. Col-0 pollen was applied to all stigmas and pollen hydration was assessed by measuring the diameter of pollen grains which become rounder in shape with water uptake. Col-0 pollen on Col-0 stigmas had a mean pollen grain diameter of $21.9 \mu \mathrm{m}$ at $10 \mathrm{~min}$ post-pollination compared to $12.6 \mu \mathrm{m}$ at $0 \mathrm{~min}$. The $b k n 1-2$ and $b k n 1-3$ mutant stigmas supported similar levels of Col-0 pollen hydration when compared to Col-0 stigmas (Fig. 2b). In contrast, Col-0 pollen place on the $b k n 2-1$ and $b k n 2-2$ mutant stigmas showed a small but significant decrease in diameter at $10 \mathrm{~min}$ postpollination. This suggested that there was a mild Col-0 pollen hydration defect on the $b k n 2-1$ and $b k n 2-2$ mutant stigmas (Fig. 2b).

To test for potential functional redundancy, double $b k n 1-b k n 2$ mutants were generated. Since the BKN1 and $B K N 2$ genes are tandemly arrayed, the strategy taken was to transform a transgene-free $b k n 1-3$ mutant with a BKN2 CRISPR construct to knock out both genes. From this screen, three new $b k n 2$ mutants, $b k n 2-3, b k n 2-4$ and $b k n 2-5$, were identified in the $b k n 1-3$ background (Fig. 2a). Pollen hydration assays were conducted on these double $b k n 1-b k n 2$ homozygous mutants, and again mild, but significant reductions were observed for the Col-0 pollen placed on these mutant stigmas (Fig. 2b). Similar to the single mutants, pollinated double $b k n 1-b k n 2$ mutant pistils stained with aniline blue displayed wild-type levels of adhered pollen 

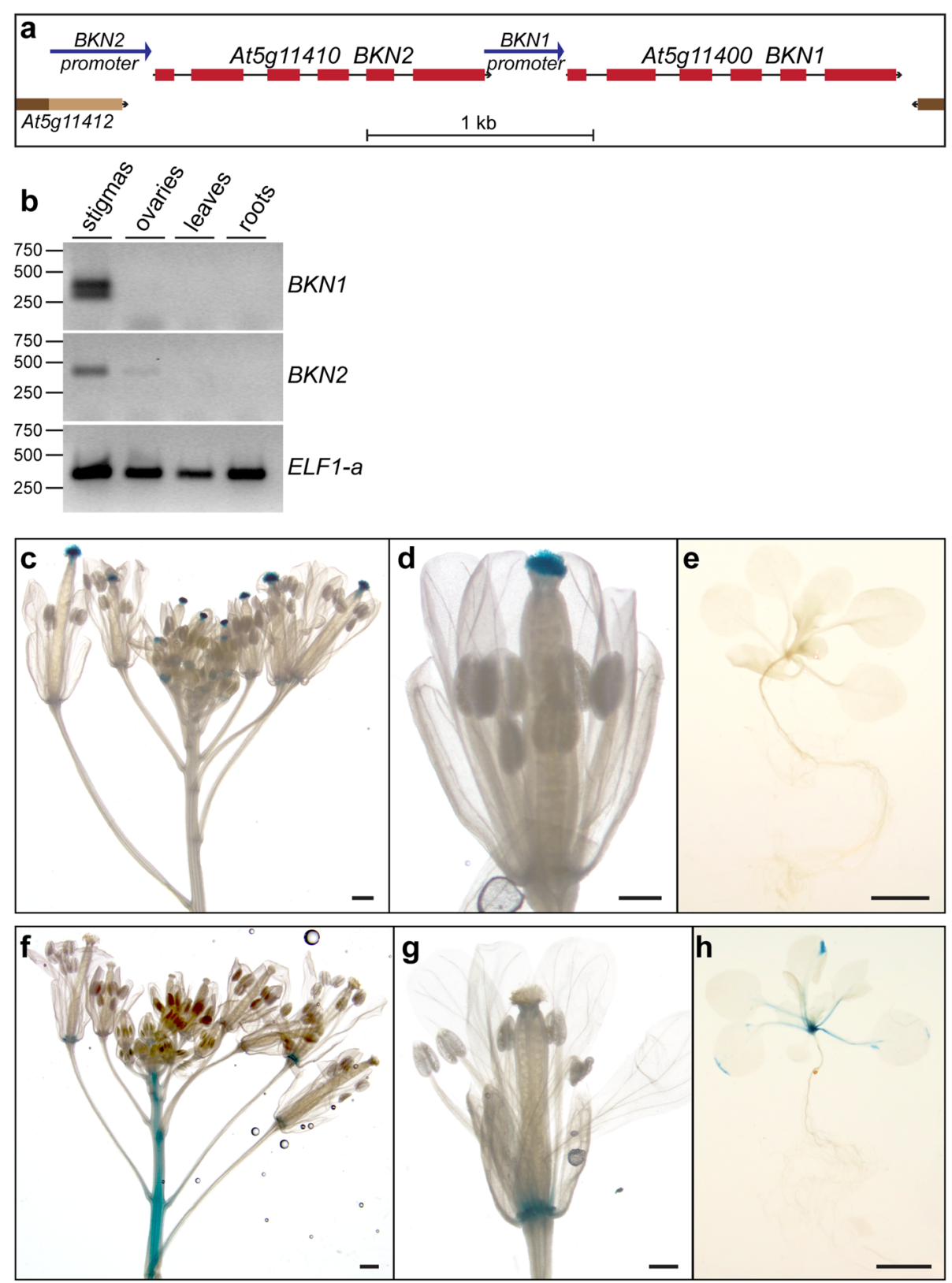

Fig. 1 Tissue-specific expression patterns of BKN1 and BKN2 in A. thaliana. a. Gene structures for the tandemly linked BKN1 and BKN2 genes. The promoter regions used for BKNp:GUS constructs are shown by blue arrows. b. RT-PCR analysis of different tissues show BKN1 and BKN2 expression in the stigmas. The double PCR bands observed for BKN1 is the result of the third intron not being properly spliced in the top band (determined by sequencing). This is also seen in the carpel RNA-Seq mapping data (Fig. 5).c-e. GUS staining of different tissues from BKN1p:GUS transgenic plants. GUS activity was specifically detected in stigmas across developmental stages in the inflorescence $(c, d)$, and not in other tissues, including seedlings (e). f-h. GUS staining of different tissues from BKN2p:GUS transgenic plants. GUS activity was detected primarily in the floral abscission zones and stems (f, g). GUS staining was also seen in the petioles and the tips of leaves for about half of the samples (h). Scale bars are $1 \mathrm{~cm}$ for inflorescence images (right), and $500 \mu \mathrm{m}$ for stage 12 flowers (centre) and $100 \mu \mathrm{m}$ for seedlings (left)

grains and pollen tube growth (Fig. 4). Thus, there did not appear to be any additive effect by knocking out both BKN1 and BKN2, and suggests that the highly expressed, stigma-specific $B K N 1$ did not display a noticeable function in pollen-stigma interactions.

\section{Variations in predicted protein translation products for $B K N 1$ in different $A$. thaliana ecotypes}

As the $b k n 1$ mutants displayed wild-type post-pollination phenotypes, the predicted protein sequences encoded by the $B K N$ genes were examined more closely. $B K N$ 

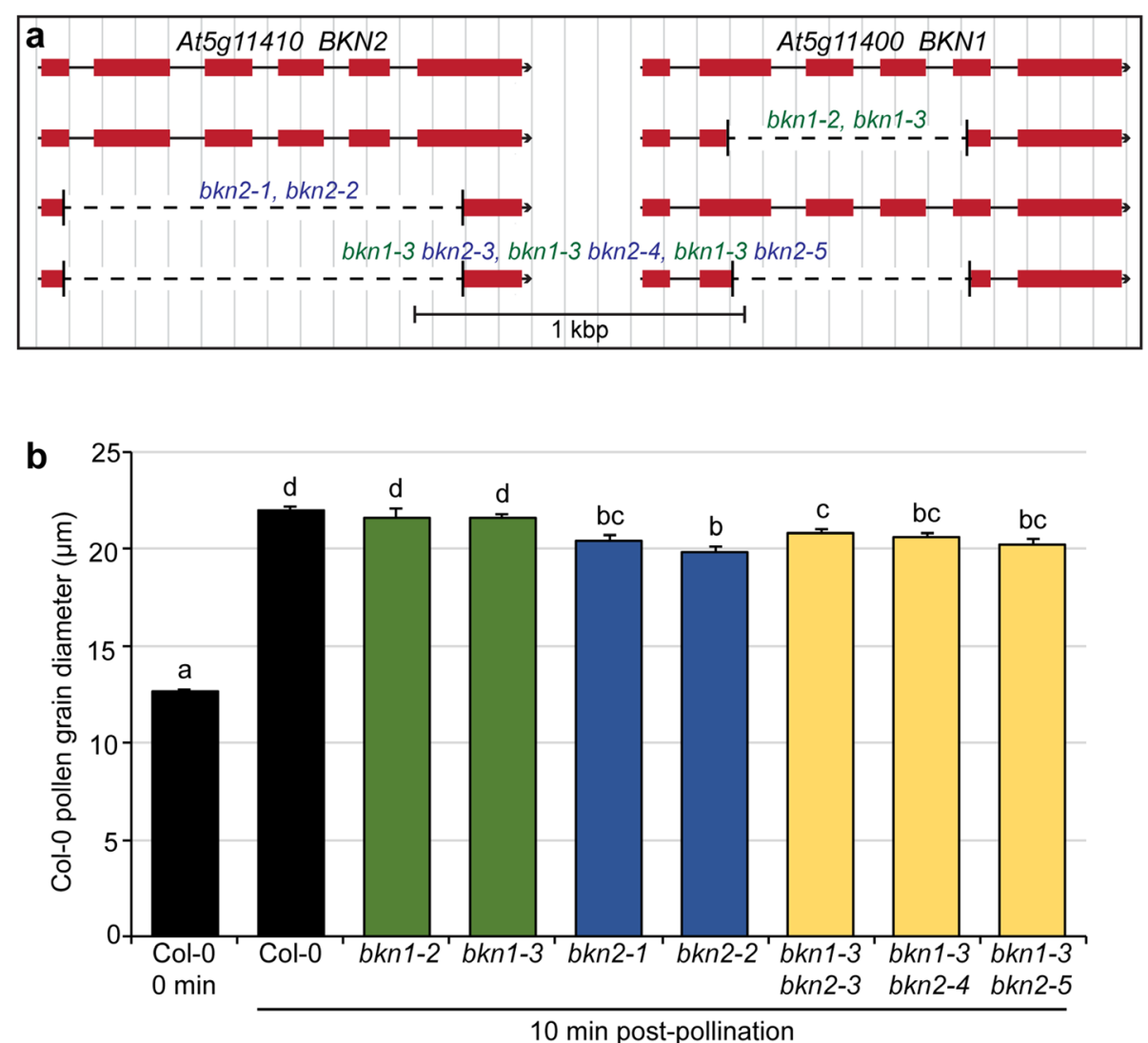

Fig. 2 Pollen hydration assays for A. thaliana Col-0 bkn1 and bkn2 CRISPR deletion mutants. a. Structure of the tandemly linked BKN1 and BKN2 genomic region depicting the locations of CRISPR deletions. The $b k n 1$ and $b k n 2$ deletion mutants were generated separately and the CRISPRgenerated deletion were confirmed by sequencing. The bkn1-3 mutant was then transformed with a CRISPR construct to delete the BKN2 gene resulting in the bkn1 bkn2 double mutants. b. Pollen hydration assays at 10 min post-pollination. Wild-type Col-0 pollen was applied to Col-0 stigmas and the different $b k n$ mutant stigmas and left for $10 \mathrm{~min}$. Pollen hydration results in a change in pollen grain diameter which was measured at 10 min post-pollination. Stigmas carrying a mutation in the BKN2 gene showed reduced Col-0 pollen hydration compared to Col-0 stigmas. $n=30$ pollen grains per line. Letters represent statistically significant groupings of $p<0.05$ based on a one-way ANOVA with a Duncan post-hoc test

cDNAs were cloned from the A. thaliana Col-0 ecotype and compared to the TAIR/Araport gene annotations [45, 49]. While the BKN2 cDNA sequence and predicted amino acid sequence matched the gene annotation, the full-length BKN1 cDNA showed some differences (Fig. 5a, Additional file 1: Figure S3). Importantly, the second exon in the cDNA included an additional $17 \mathrm{bp}$ at the $5^{\prime}$ end resulting in a frameshift and a premature stop codon (Fig. 5a, asterisk). As a result, the predicted A. thaliana Col-0 BKN1 protein would only be 42 aa in length, in comparison to the predicted 304 aa (Additional file 1: Figure S4). The cloned BKN1 cDNA matched the carpel RNASeq mapping data displayed on Araport (Fig. 5a); nevertheless, there also appeared to be potential alternative splice sites at the beginning of the second exon that could restore the BKN1 reading frame and encode a larger protein (i.e. the BKN1 gene annotations; yellow arrow in Fig. 5a; Additional file 1: Figure S3, S4). While two BKN1 RT-PCR bands were observed in Fig. 1b, the larger band was identified by sequencing to include the third intron, rather than an alternatively spliced transcript. Signs of the unspliced third intron were also present in the carpel RNA-Seq mapping displayed on Araport (orange arrow in Fig. 5a). Despite several attempts, we were unable to clone BKN1 cDNAs that corresponded to the TAIR/Araport gene annotations.

A search for $B K N$ orthologues in the genomes of two outcrossing Arabidopsis species, A. lyrata, and A. halleri, uncovered $B K N 1$ coding regions that were predicted to be fully intact. This was confirmed by cloning the corresponding cDNAs from $A$. lyrata (Additional file 1: Figure S3, S4 and S5). When the $B K N 1$ sequences were aligned, two indels were identified in the A. thaliana Col-0 BKN1 cDNA sequence 


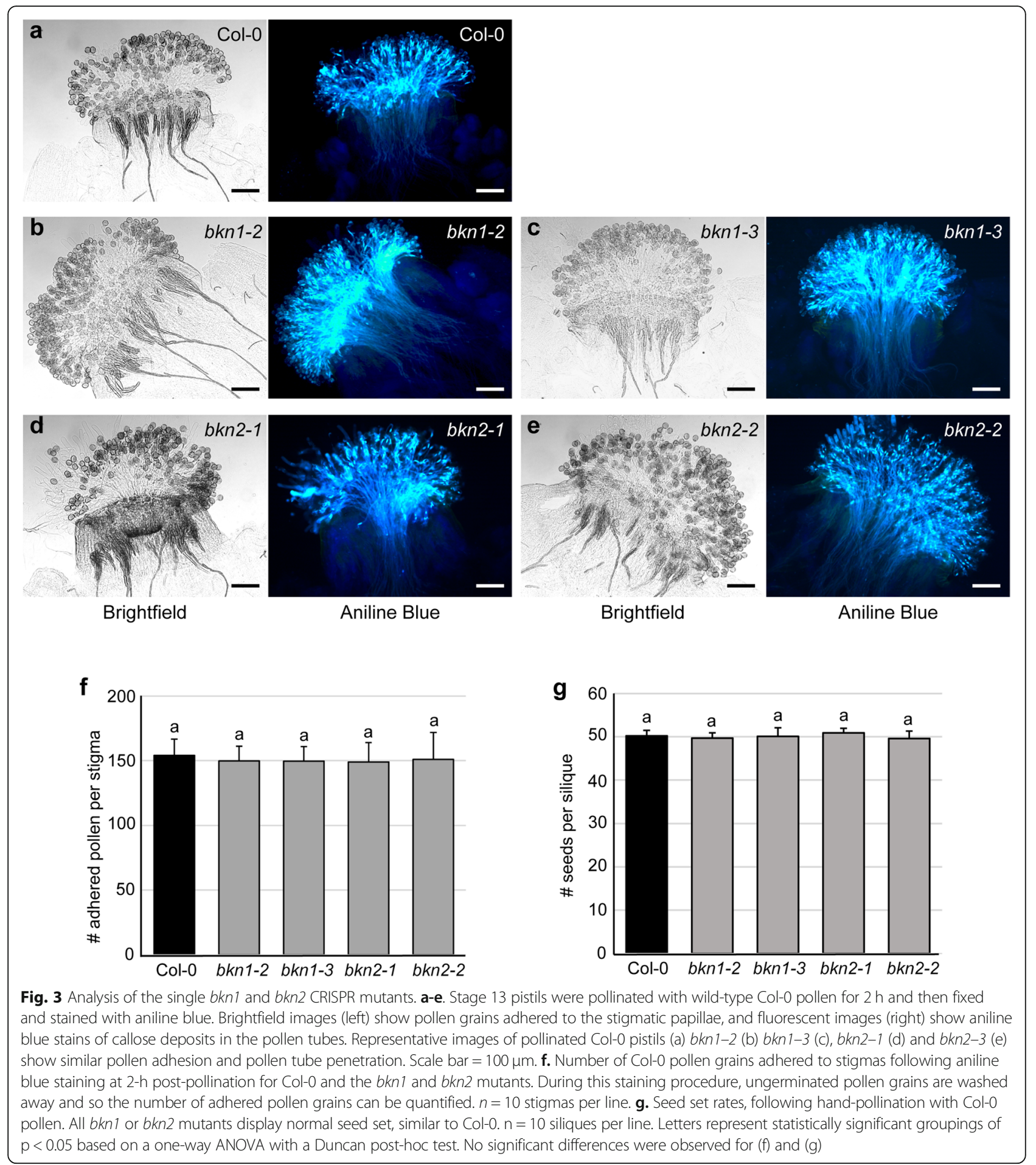

that would disrupt the reading frame (Fig. 5, asterisks), the first being a $1 \mathrm{bp}$ deletion $(\Delta \mathrm{T} 128)$ and the second being a $1 \mathrm{bp}$ insertion (^A597; Additional file 1: Figure S3). We then searched through the 1135 genomes dataset to determine how widespread these $B K N 1$ indels were across the different $A$. thaliana ecotypes [50]. Most ecotypes carried $\Delta \mathrm{T} 128$ causing the premature stop codon in Col-0 BKN1 (Additional file 3: Table S2). Interestingly, three A. thaliana ecotypes were predicted to have fully intact $B K N 1$ coding regions. The first ecotype identified was Hh- 0 , and the corresponding cDNA was cloned and confirmed by sequencing to encode a full-length BKN1 protein, similar to Al-BKN1 (Fig. 5, Additional 


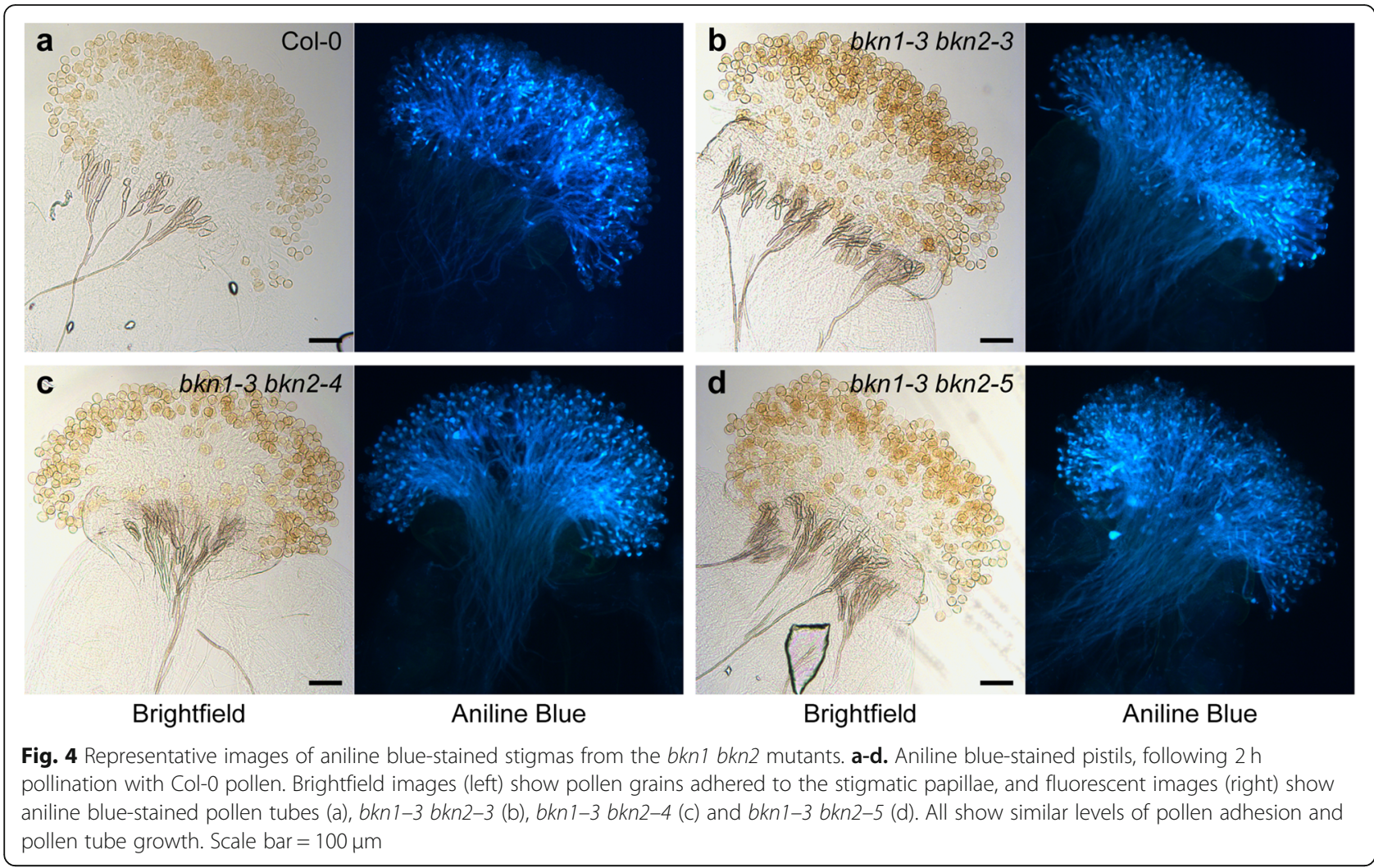

file 1: Figure S3, S4 and S5). Subsequent searches identified two other ecotypes, Dju-1 and Västervik, that were also confirmed to carry the same two indels as $\mathrm{Hh}-0$ to encode a full-length BKN1 protein (Fig. 5b, Additional file 1: Figure S6, Additional file 3: Table S2). However, in a number of other ecotypes, the presence of the two ORF-restoring indels $\left({ }^{\wedge} \mathrm{T} 128, \Delta \mathrm{A} 597\right)$ were associated with new SNPs that would again knock out the $B K N 1$ coding region. This included the loss of the start methionine (ATG $\rightarrow$ ACG) and a new stop codon (TAA) downstream of $\triangle$ A597 (Fig. 5, Additional file 1: Figure S6, Additional file 3: Table S2). With Hh-0 expressing an intact At-BKN1 gene, pollen hydration assays were conducted on Hh-0 flowers to see if there was any variation at this early post-pollination stage and then compared to Col-0 in reciprocal pollinations, but no obvious differences were observed (Additional file 1: Figure S7).

\section{BKNs are conserved within the Brassicaceae but are absent in species outside this family}

Given the BKN1 polymorphisms found in the Arabidopsis species genomes, we also investigated related $B K N$ genes in other plant species. The BKNs are part of the group VII RLCKs (Additional file 1: Figure S8; as defined by [51]) which include a number of important signalling proteins such as the BOTRYTIS-INDUCED KINASE1 (BIK1 [52]) and the various PBS1-Like (PBL) proteins associated with plant immune signalling $[53,54]$. The BKNs are most closely related to CASTAWAY (CST [55]) and PBL31 [53] (Additional file 1: Figure S8). RLCKs are related to plant receptor kinases $[51,56]$, except that they lack extracellular domains and typically function in complexes with receptor kinases [57-59]. Alignments between BKN1 and BKN2 with CST (an active kinase involved in floral abscission [55]) clearly show that the BKNs are missing several key residues for ATP binding and catalytic activity, including the glycine-rich loop and the VAIK, HRD and DFG motifs, and as a result, are defined as being pseudokinases [46] (Additional file 1: Figure S9). Although some pseudokinases may exhibit partial kinase activity, BKNs are predicted to be inactive due to the number of missing residues, particularly the glycine-rich loop and the VAIK motif, which are required for catalytic activity $[46,60]$.

To investigate the distribution of $B K N$ genes in plant genomes, BLAST searches were conducted using the $A$. thaliana BKN amino acid sequences along with three closely related RLCK amino acid sequences: At5g25440, PBL31 (At1g76360) and CST (At4g35600). These three predicted proteins were selected as they cluster with the BKNs in the RLCK-VII tree (Additional file 1: Figure S8). In these searches, a third A. thaliana BKN paralogue was located nearby on chromosome 5, At5g11360 


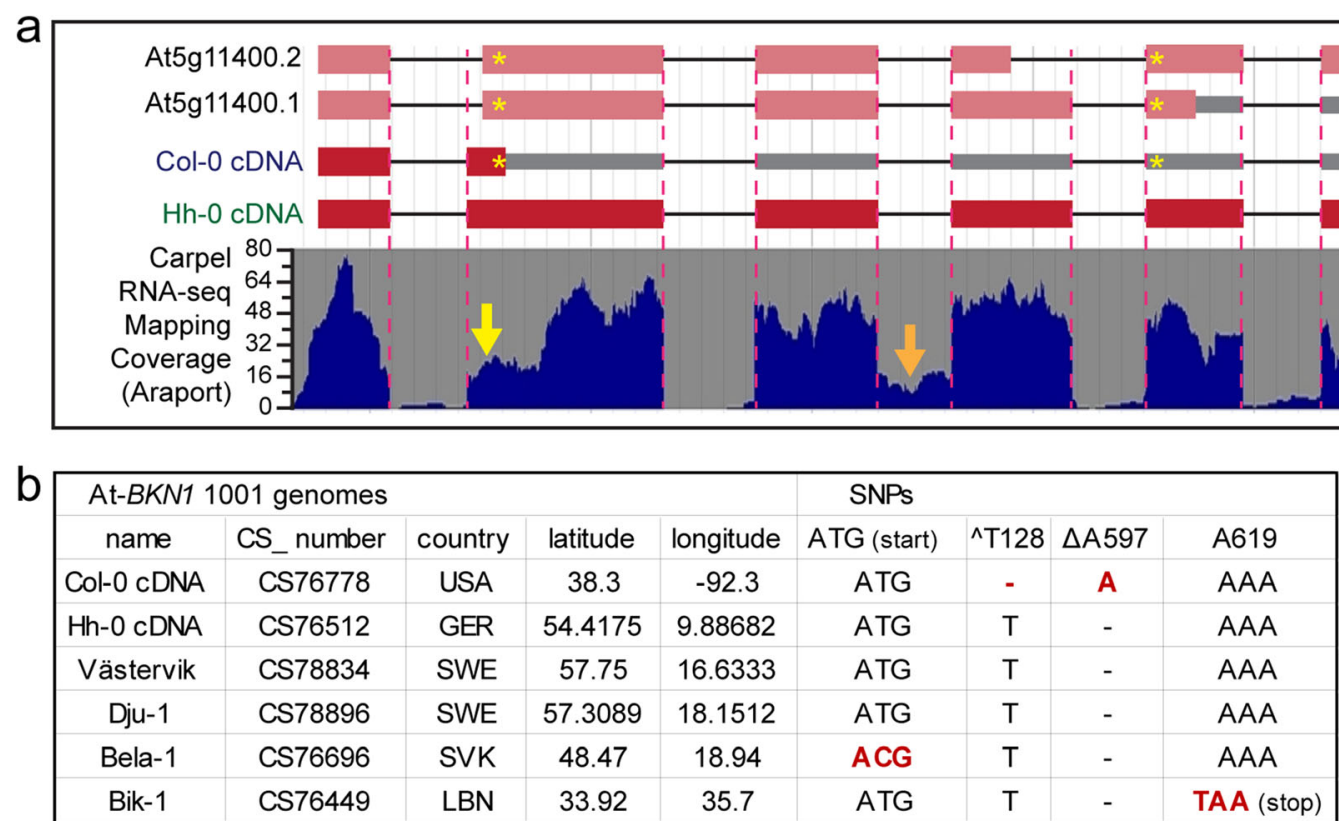

Fig. 5 A. thaliana BKN1 gene models and ecotype polymorphisms. a. A. thaliana BKN1 gene models are shown with carpel RNA-Seq mapping coverage from Araport [45]. Yellow astericks (*) mark two in/del SNPs in Col-0 BKN1 when compared to Hh-0 BKN1 and A. lyrata BKN1. For the BNK1 Col-0 gene annotations and CDNA, the first asterisk marks a 1 bp deletion (T) resulting in an adjacent premature stop codon and the second asterisk marks a 1 bp insertion (A) that would result in a downstream premature stop codon for the At5g11400.1 annotation. Based on the reduced carpel RNA-Seq coverage at the $5^{\prime}$ end of the BKN1 exon 2, there may be alternate splice sites in use (yellow arrow) and some of these potential alternate splice junctions would restore the BKN1 Col-0 reading frame to produce a longer protein as predicted for the At5g11400.1 and At5g11400.2 annotations. See also Additional file 1: Figure S3 and S4. The orange arrow delineates the third intron that is not properly spliced in the top RT-PCR band in Fig. 1b. b. A. thaliana BKN1 polymorphisms in different ecotypes. In addition to Hh-0, Västervik and Dju-1 are predicted to encode a full length BKN1 protein (based on genomic sequencing). Bela-1 and Bik-1 displayed other SNPs that disrupt the BKN1 open reading frame (see also Additional file 1: Figure S6)

(BKN3; Additional file 1: Figure S4). At-BKN3 is predicted to have a large internal deletion of $\sim 140$ amino acids, while the corresponding orthologues in A. lyrata and $A$. halleri encode a full length BKN3s (Additional file 1: Figure S4 and S5). We identified BKN homologues for all Brassicaceae genomes searched, including A. lyrata, A. halleri, Arabis alpina, Boechera stricta, Capsella rubella, C. grandiflora, Brassica cretica, B. oleracea, Eutrema salsugineum (formerly Thellungiella halophila) and Schrenkiella parvula (formerly T. parvula). The number of homologues ranged from one in S. parvula to nine in B. oleracea. Interestingly, the BKNs were all predicted to be the pseudokinases (Additional file 1: Figure S9) and only found in core Brassicaceae genomes, not in the genome of the basal Brassicaceae species, Aethionema arabicum [61]. Our searches were expanded to include two genomes from other Brassicales families (Tarenaya hassleriana, Cleomaceae; Carica papaya, Caricaceae), and a phylogenetic analysis of the retrieved sequences indicated an absence of $B K N$ homologues in these genomes as well (Fig. 6). All of the core Brassicaceae BKNs were found in a clade that was distinct from the homologues for the other group VIIa RLCKs (At5g25440, CST, PBL31; Fig. 6).
Plasma membrane localization of BKNs by predicted Nterminal myristoylation and palmitoylation sites

Despite lacking kinase activity, pseudokinases do play a variety of roles in biological systems and typically are in association with other signalling proteins at the cell membrane [66-74]. While the BKNs, as typical RLCKs, lack extracellular and transmembrane domains, they have conserved residues for $\mathrm{N}$-terminal myristoylation and/or palmitoylation. These N-terminal lipid anchors can target proteins to the cell membrane where they would be proximal to other signalling proteins and receptors [75-77]. The presence of a glycine at position two is essential for myristoylation, while the cysteine at position 4 is required for palmitoylation [78]. Interestingly, all the Brassicaceae BKN homologues have a predicted myristoylation site (G2, Additional file 1: Figure S9) while several also have a predicted palmitoylation site at the N-terminus (C4; Additional file 1: Figure S9). Specifically, A. thaliana BKN1, A. thaliana BKN2 and A. lyrata BKN2 have both the $\mathrm{G} 2$ and $\mathrm{C} 4$ sites while A. lyrata BKN1 only has the G2 myristoylation site (Additional file 1: Figure S5 and S9). Using a transient expression system in Nicotiana benthamiana leaf epidermal cells, C-terminal YFP fusions [79] of the four 


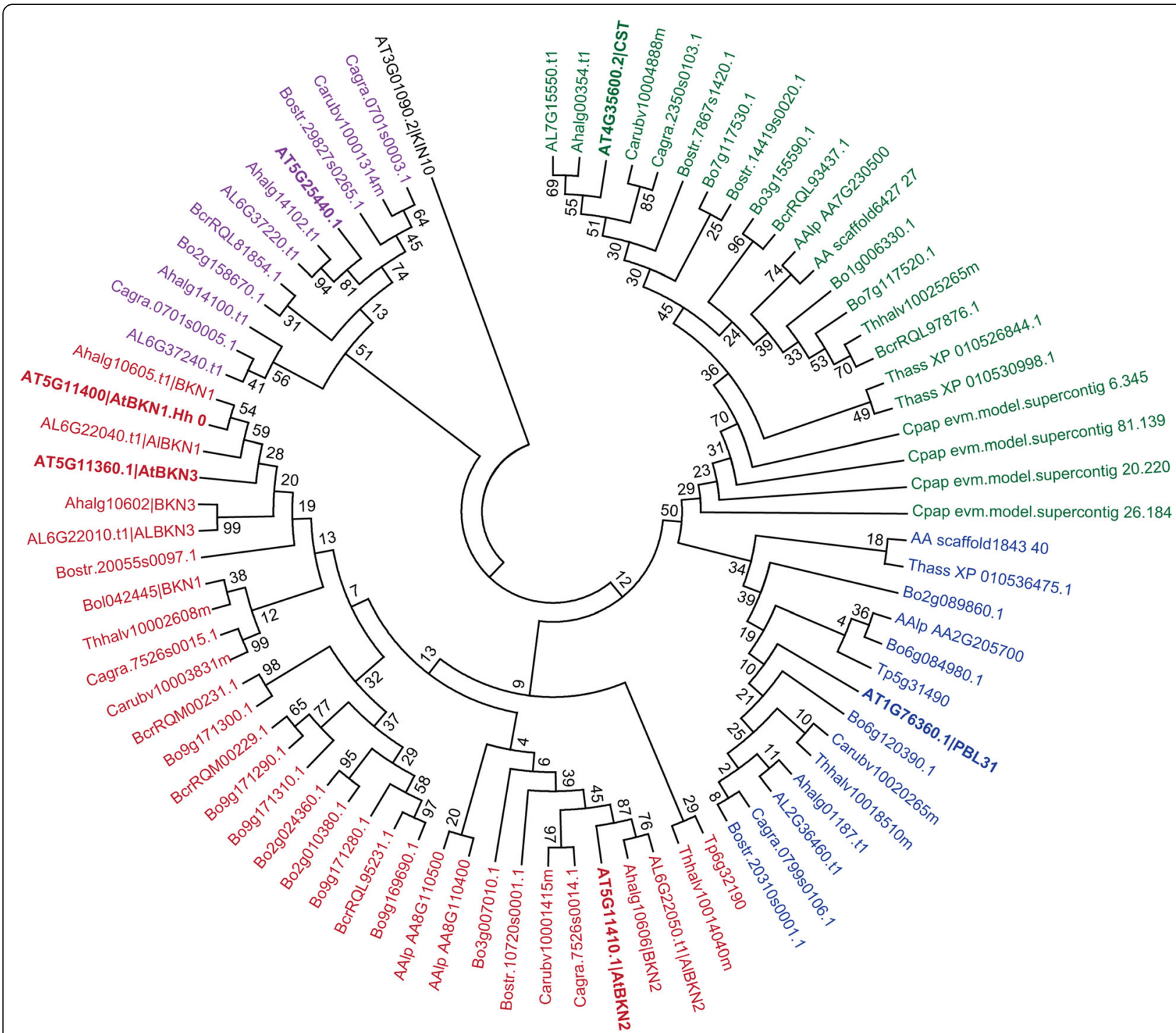

Fig. 6 Phylogenetic analysis of Brassicaceae BKN and closely-related RLCK group VIla protein sequences. Sequences are from Arabidopsis thaliana, A. Iyrata, A. halleri, Arabis alpina, Boechera stricta, Brassica cretica, B. oleracea, Capsella rubella, C. grandiflora, Eutrema salsugineum (formerly T. halophila), Schrenkiella parvula (formerly T. parvula), Aethionema arabicum, Tarenaya hassleriana, and Carica papaya. Red branches represent the BKN clade, Magenta branches represent the At5g25440-related RLCKs, Blue branches represent the At1g76360-related RLCKs, Green branches represent the CST (At4g35600)-related RLCKs. A. thaliana protein sequences for At5g25440.1, At1g76360.1 and At4g35600.2 were selected for searches and phylogenetic analyses as they clustered with the BKNs in the RLCK-VIla tree (Additional file 1: Figure S7). KIN10 (At3g01090.2, SnRK1 kinase) was chosen as an outgroup. The analysis involved 90 amino acid sequences and the sequences were aligned using ClustalW [62] in the MEGA 7 software [63]. The N-and C-terminal ends of the alignment were trimmed (see Supplemental files for sequences and alignment), and the tree was constructed using the Maximum Likelihood method [64] in the MEGA 7 software. All positions containing gaps and missing data were eliminated, and a total of 28 positions was in the final dataset. The tree generated in MEGA 7 represents the bootstrap consensus tree inferred from 1000 replicates [65]

proteins were then tested for potential plasma membrane localization. Full-length At-BKN1 from Hh-0 was tested along with At-BKN2 from Col-0, Al-BKN1 and Al-BKN2 (Fig. 7). All four BKN:YFP proteins appeared to be predominantly localized to the plasma membrane (Fig. 7a-d), with At-BKN1:YFP and Al-BKN1:YFP also showing some localization to the nucleus (Fig. 7a-b). It was unclear whether the unexpected partial nuclear localization is related to the protein function or an artifact caused by cleavage and mis-localization of the YFP. As well, AlBKN1:YFP's pattern of localization to the plasma membrane did not appear to be as tight as the other BKNs, but this may be related to Al-BKN1 only having a myristoylation site [81]. Myristoylation allows for transient associations with the membrane while the combination of palmitoylation and myristoylation more effectively 


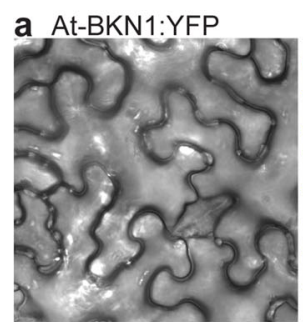

\section{c At-BKN2:YFP}

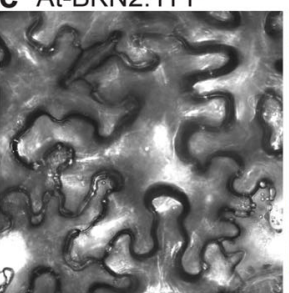

\section{e $A I-B K N 2(G 2 A): Y F P$}
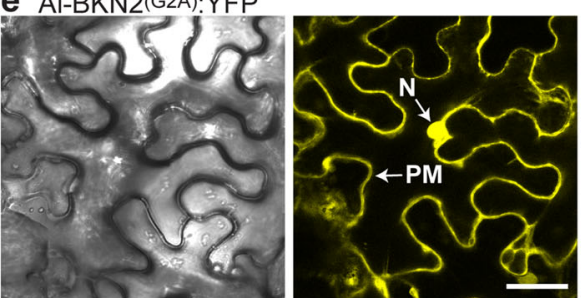

g Al-BKN2(G2A,C4A):YFP
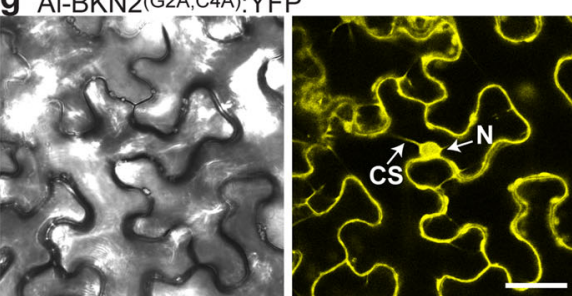

i Al-BKN2:YFP plasmolysed
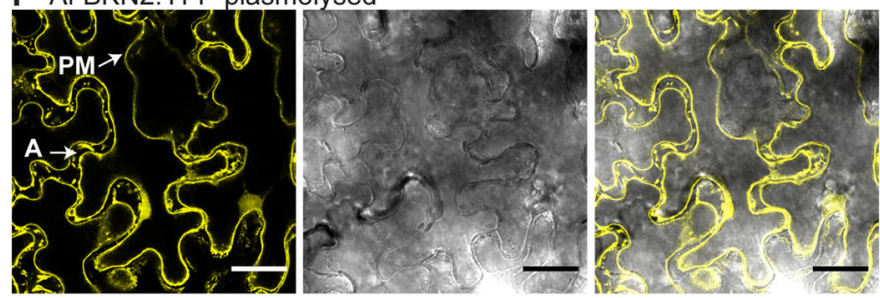

d Al-BKN2:YFP

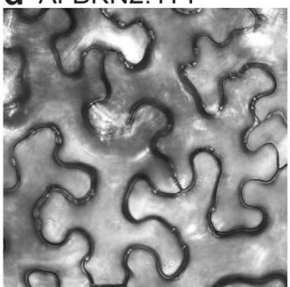

f $\mathrm{Al}-\mathrm{BKN} 2(\mathrm{C} 4 \mathrm{~A}): \mathrm{YFP}$

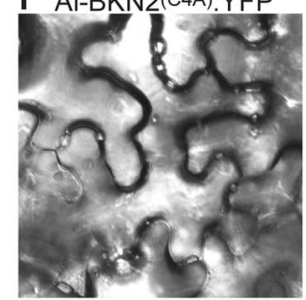

h At-CAM4:YFP

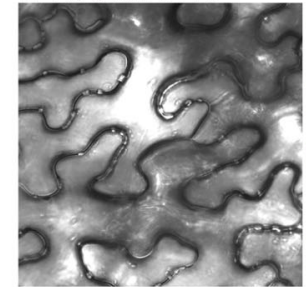

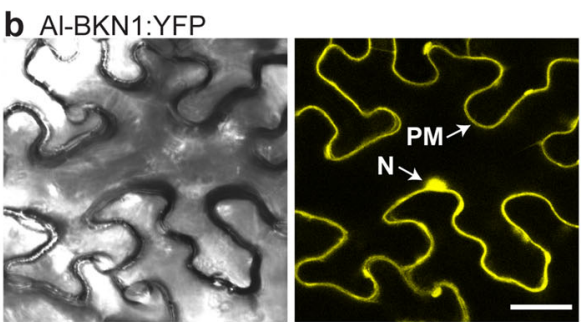
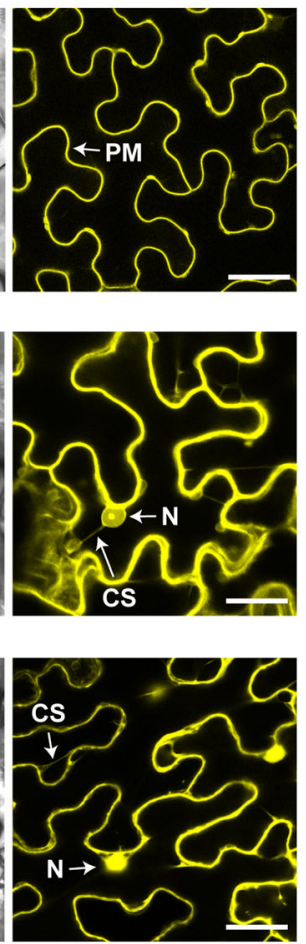

Fig. 7 Confocal microscopy imaging of $N$. benthamiana leaves infiltrated with C-terminal BKN:YFP fusion proteins. a-b. BKN1 is predominantly localized to the plasma membrane (PM) with some nuclear localization (N) for both At-BKN1 (a) and Al-BKN1 (b). The BKN1 cDNA from the Hh-0 ecotype was used for expressing the At-BKN1 protein (see text). c-d. BKN2 is predominantly localized to the plasma membrane (PM) for both At-BKN2 (c) and Al-BKN1 (d).e-g. Plasma membrane localization is disrupted for Al-BKN2 versions mutated at the myristoylation (G2A) and palmitoylation (C4A) sites. Images are shown for the single G2A mutant (e), single C4A mutant (f) and double G2A C4A mutant (g) versions of Al-BKN2. Localization is seen in the cytoplasm (CS = cytoplasmic strands) and nucleus (N). h. A. thaliana CAM4:YFP was used to compare the localization of YFP fluorescence in the cytoplasm (CS = cytoplasmic strands) and nucleus (N). i. Cells infiltrated with Al-BKN2 were plasmolysed using $0.8 \mathrm{M}$ mannitol. Localization in plasmolysed cells remains predominantly at the cell periphery. There is also some localization to Hechtian strands in the apoplastic space (A). Hechtian strands are plasma membrane tubules connected to the cell wall [80]. YFP fusion constructs were infiltrated at OD600 $=0.5$, and images were taken $24 \mathrm{~h}$ post-inoculation. Scale bars $=30 \mu \mathrm{m}$

anchors proteins to the plasma membrane, though these protein modifications remain reversible to facilitate transient membrane associations [81].
With Al-BKN2:YFP and At-BKN2:YFP containing both the $\mathrm{G} 2$ and $\mathrm{C} 4$ sites and showing strong plasma membrane localization, we also tested if these proteins 
could be palmitoylated when expressed in yeast cells. The BKN2 proteins were isolated from transformed yeast cells (Fig. 8a), and then tested for $S$-palmitoylation using the in vitro acyl-RAC (resin-assisted capture) assay [82]. After free thiols were blocked, the proteins were either treated with hydroxylamine (+) to remove palmitoylate and exposing free thiols at the palmitoylation sites or left untreated (-). Both Al-BKN2 and At-BKN2 were detected in the $(+)$ lanes indicating that these proteins had been S-palmitoylated and were captured on the thiol-reactive resin following hydroxylamine treatment (Fig. 8b). Finally, since Al-BKN2:YFP displayed particularly high florescent levels as well as strong localization to the plasma membrane (Fig. $7 \mathrm{~d}$ ), we tested the effects of disrupting the myristoylation and palmitoylation sites on its localization pattern. Amino acid substitutions of the myristoylation (G2A) site, the palmitoylation (C4A) site or both $(\mathrm{G} 2 \mathrm{~A}, \mathrm{C} 4 \mathrm{~A})$ in Al-BKN2:YFP disrupted its plasma membrane localization, resulting in mislocalization to the nucleus and the cytoplasm of $N$. benthamiana leaf epidermal cells (Fig. 7e-g), similar to the CAM4:YFP control (Fig. 7h). The cells infiltrated with Al-BKN2:YFP were also plasmolysed by treating with 0.8 $M$ mannitol to cause cell shrinkage and plasma membrane dissociation from the cell wall. BKN2:YFP localization was observed at the plasma membrane, at the sites where the plasma membrane has detached from the cell wall, and with Hechtian strands in the apoplastic space (Fig. 7i). Similar results were observed for the other BKNs following plasmolysis (Additional file 1: Figure S10). With the Al-BKN2 versions mutated at the myristoylation (G2A) and/or palmitoylation (C4A) sites, disrupted plasma membrane localization was again observed in the plasmolysed cells with the YFP signal becoming more diffuse and some localization occurring in the nucleus (Additional file 1: Figure S10). Thus, this data strongly supports that the BKNs have N-terminal lipid anchors to localize to the plasma membrane, and disruption of the fatty acid modification sites (G2, C4) causes a mis-localization to other subcellular compartments.

\section{Discussion}

In this study, we have investigated a novel family of pseudokinase genes, the BRASSIKINs (BKNs) that are only found in core-Brassicaceae species. The Brassicaceae genomes examined typically carried two to three different $B K N$ genes, except for the Brassica genomes which tended to have higher numbers, up to nine predicted $B K N$ genes for the diploid species. BKNs belong to the receptor-like cytoplasmic kinase (RLCK) subfamily, and as such lack an extracellular domain required for external signal perception. RLCKs play diverse roles in plant cell signalling often through interactions with receptor kinases [57, 58], and so it is conceivable that BKNs function in a receptor kinase complexes for signaling pathways. For instance, $A$. thaliana CASTAWAY (CST) is a plasma membrane localized RLCK that has been shown to interact with two receptor kinases, HAESA and EVERSHED, and function as an inhibitor of floral organ abscission [55]. CST also localized to the plasma membrane through $\mathrm{N}$-terminal myristoylation and palmitoylation sites, and this localization pattern was shifted towards the cytoplasm when the $\mathrm{N}$-terminal lipid anchor sites were mutated [55]. Here, we have shown that BKN1 and BKN2 have predicted N-terminal palmitoylation and/or myristoylation sites and localized to the plasma membrane in $N$. benthamiana epidermal cells. As well, yeast-expressed BKN2 was confirmed to

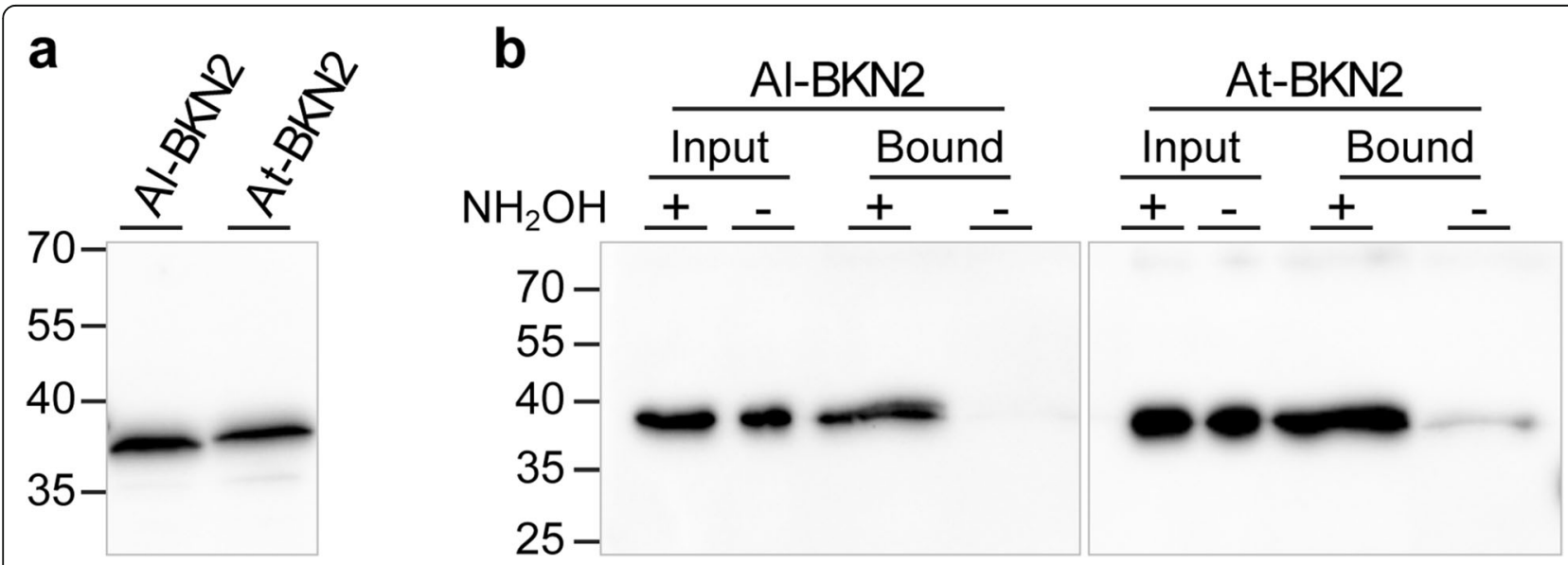

Fig. 8 Palmitoylation of Al-BKN2 and At-BKN2. (a) Protein expression and (b) Palmitoylation assay for Al-BKN2 and At-BKN2. BKN2 proteins were purified from yeast cells and tested for S-palmitoylation using the in vitro acyl-RAC assay [82]. The BKN2 proteins were detected via C-terminal V5 epitope tags and western blotting with an anti-V5 antibody. The presence of a band in the $+\mathrm{NH}_{2} \mathrm{OH}$ bound lanes indicates that both BKN2 proteins were palmitoylated when expressed in yeast cells 
be palmitoylated using the in vitro acyl-RAC assay. Finally, we observed that mutations of the myristoylation and palmitoylation sites for Al-BKN2 disrupted membrane localization in $N$. benthamiana epidermal cells. Thus, the plasma membrane localization of BKN1 and BKN2 could position these RLCKs for interactions with receptor complexes.

While many RLCKs, such as CST, are functional kinases, the BKNs are predicted to be pseudokinases meaning that they lack the catalytic motifs required for phosphotransfer [46, 60]. There are examples of pseudokinases with very low levels of autophosphorylation activity and this typically requires the catalytic lysine of the VAIK motif, and usually the aspartates of the HRD and DFG motifs as well [46]. In addition, while most pseudokinases are devoid of catalytic activity, it is estimated that close to $40 \%$ of all pseudokinases are capable of nucleotide binding [46]. However, the BKNs lack all of the key motifs required for ATP binding and catalytic activity, including VAIK with the key catalytic lysine as well as the HRD and DFG motifs $[46,60]$. In a recent study, 168 of the 1005 Arabidopsis predicted kinases were classified as pseudokinases [47]. A number of these Arabidopsis pseudokinases (also referred to as atypical kinases [83]) have been shown to have biological functions related to signalling [66-74, 84, 85]. One example is the Brassinosteroid Signalling Kinases (BSKs), which are a group of 12 closely-related, functionally redundant cytoplasmic pseudokinases involved in brassinosteroid signalling through interactions with the receptor BRI1 [66, $67,86]$. The BSKs are phosphorylated by the BRI1 receptor kinase during BR hormone perception and are proposed to function as scaffolds in the signaling complex $[67,87]$. Another example is the stem cell signalling protein CORYNE (CRN) which interacts with the receptor CLAVATA 2 to promote localization to the plasma membrane [88] and functions with receptor kinases to regulate stem cell fate in the shoot and root apical meristems $[68,69,89]$. Finally, roles for pseudokinases have been defined in immune complexes that regulate plant immunity responses [70, 84, 85, 90]. Interestingly, Liu et al. [91] recently discovered a role for BKN2 in plant immunity (SUPPRESSOR OF ZED1-D2; SZE2) and found that it was localized to the plasma membrane as part of an immune complex. Thus, given the tendency of pseudokinases to function in protein complexes, potential interactors will need to be identified in the stigma to further understand the functions of BKNs.

Our interest in the BKN family started with a search for stigma-enriched signalling proteins that may function in compatible pollen responses, and this search led to the identification of the stigma-specific BKN1 in $A$. thaliana Col-0. However, the $b k n 1$ mutants in the Col-0 ecotype did not display any detectable changes in compatible pollen responses and only a mild-hydration defect was observed when wild-type Col-0 pollen was placed on mutant $b k n 2$ stigmas (a tandemly linked paralogue). In addition, the level of impairment did not increase for the $b k n 1-b k n 2$ double mutant stigmas. This was rather puzzling since $B K N 2$ was only expressed at a low level in the stigma, particularly in comparison to $B K N 1$. Further investigations uncovered that the $B K N 1$ gene in most $A$. thaliana ecotypes carried two indels, $\Delta \mathrm{T} 128$ and ${ }^{\wedge} \mathrm{A} 597$, that would cause frameshifts in the BKN1 coding region resulting a loss of full-length protein. Interestingly, three ecotypes, Hh-0, Dju-1 and Västervik, were found to carry two ORF-restoring SNPs $\left({ }^{\wedge} \mathrm{T} 128\right.$ and $\left.\triangle \mathrm{A} 597\right)$ and predicted to encode a fulllength BKN1 protein. Furthermore, two outcrossing Arabidopsis species, A. lyrata and A. halleri, also carry $B K N 1$ orthologues that are predicted to encode fulllength BKN1 proteins. These combined results raise a few questions for further investigation. Does the mild hydration phenotype associated with $b k n 2$ mutants point to a related function for $B K N 1$ that was lost during the transition to selfing for $A$. thaliana? For example, is BKN1's stigma function related to pollen-stigma interactions in outcrossing species? The evolution from outcrossing to selfing occurs under different selective mechanisms, such as reduced access to pollinators or population bottlenecks associated with colonization of new environments, and is associated with the loss of self-incompatibility in Brassicaceae species (reviewed in $[92,93])$. The transition to selfing is also associated with a change in several floral traits termed the 'selfing syndrome' and includes changes in flower size and shape (small flowers) and reduced pollen numbers, as seen in comparisons between outcrossing A. lyrata/A. halleri and selfing $A$. thaliana [93-95]. Other changes associated with the 'selfing syndrome' include loss of pollinator attraction traits (reviewed in [93, 95]).

Specifically related to selfing, there are traits, in the addition to the loss of self-incompatibility, that can be modified to improve self-pollination in the transition to selfing. These include dichogamy (temporal differences between time of pollen release and stigma receptivity), herkogamy (height differences between to stigma and anthers to prevent self-pollination) and anther orientation (anther surface undergoing dehiscence is oriented away from stigma) $[93,95,96]$. A. lyrata and A. halleri are self-incompatible species, whereby they exhibit a tight control of outcrossing through the linked S-locus protein 11/S cysteine-rich and $S$ receptor kinase polymorphic genes (reviewed in [16]). With both species carrying intact $B K N 1$ genes, it would be of interest to investigate a potential role in stigma-pollen interactions in the context of these different traits designed to avoid self-pollination. As well, some North American A. lyrata 
populations around the Great Lakes region have also shifted towards self-compatibility, but show no significant changes towards the selfing syndrome [97-99]. These self-compatible $A$. lyrata may also be interesting to compare loss-of-function $B K N 1$ mutations in the context of self-pollination. Finally, the recent discovery of a role for BKN2/SZE2 in plant immunity [91] opens another direction of inquiry. Related to this, dual roles have been uncovered for other signaling proteins in both plant reproduction and pathogen responses [5]. The relative ease with which CRISPR/Cas9 technology can be used to create loss-of-function mutants opens the door to asking these questions regarding BKN1 function in other A. thaliana ecotypes and Arabidopsis species in the future.

\section{Conclusions}

In this study, we have identified a novel family of Brassicaceae-specific pseudokinase genes, termed BRASSIKINs, and specifically focused on the function of the tandemly linked $B K N 1$ and $B K N 2$ genes, in the context of pollen-stigma interactions in $A$. thaliana Col-0. CRISPR deletion mutants were generated, and very mild hydration defects were observed for wild-type Col-0 pollen when placed on the $b k n 2$ and $b k n 1 / 2$ mutant stigmas. Polymorphisms leading to premature stop codons were uncovered for BKN1 in many A. thaliana ecotypes including Col-0 while absent in outcrossing Arabidopsis species. Thus, future studies should focus on examining BKN1 function in other A. thaliana ecotypes and Arabidopsis species.

\section{Methods}

Plant materials and growth conditions

Seeds for the A. thaliana bkn1-1 T-DNA insertion mutant (Col-0, SALKseq_039336), and the A. thaliana Hh0 (CS76512), Västervik (CS78834), Dju-1 (CS78896) and Bela-1 (CS76696) ecotypes were obtained from Arabidopsis Biological Resource Center (ABRC). Seeds for the A. thaliana Col-0 ecotype and $N$. benthamiana were obtained from Dr. Nambara and Dr. Yoshioka, respectively (University of Toronto). A. thaliana seeds were sterilized and cold stratified for at least 2 days at $4{ }^{\circ} \mathrm{C}$, then transferred to soil or plated on $1 / 2$ Murashige and Skoog (MS) medium plates with $0.4 \%(\mathrm{w} / \mathrm{v})$ phytoagar at $\mathrm{pH} 5.8$ at $22{ }^{\circ} \mathrm{C}$ under $16 \mathrm{~h}$ light. After 7-10 days, seedlings were transferred to soil supplemented with $1 \mathrm{~g} / \mathrm{L}$ 20-20-20 fertilizer and grown at $22{ }^{\circ} \mathrm{C}$ under $16 \mathrm{~h}$ light. For the $A$. thaliana bkn1-1 T-DNA insertion mutant (SALKseq 039336), homozygous mutants were confirmed by PCR, and the location of the T-DNA was verified by sequencing of PCR products. $N$. benthamiana seeds were cold stratified for several days and planted directly on soil, and grown at $22^{\circ} \mathrm{C}$ under $16 \mathrm{~h}$ light conditions.
Humidity was monitored and maintained at between 20 to $60 \%$ relative humidity in the growth chambers.

\section{Plasmid construction and plant transformation}

The $371 \mathrm{bp} B K N 1$ predicted promoter consists of the untranslated region immediately following the $B K N 2$ coding region to the $B K N 1$ start codon. The $B K N 2$ predicted promoter covers $465 \mathrm{bp}$ upstream of the $B K N 2$ start codon, including the 3'UTR for At5g11412. The $B K N 1$ and $B K N 25^{\prime}$ predicted promoter regions were synthesized by GeneArt gene synthesis services (ThermoFisher Scientific). The promoters were cloned into the pORE-R2 vector upstream of the GUS coding region through XhoI and NotI sites, [100], transformed into Arabidopsis thaliana Col-0 by floral dip [101]. T1 seeds were selected for kanamycin resistance on $1 / 2$ MS medium plates containing $50 \mu \mathrm{g} / \mathrm{ml}$ kanamycin. Inflorescence or stage 12 flowers from several T1 plants were stained for GUS activity (see below).

For the CRISPR/Cas9 generated mutants, a two-sgRNA (single guide RNA) system was used to generate genomic deletions in the BKN1 and BKN2 genes [48]. The CRISPR sgRNA sequences targeting $B K N 1$ or $B K N 2$ were selected using the $\mathrm{CHOPCHOP}$ software to search for sequences adjacent to PAM sites and avoid potential off-targets in the A. thaliana genome [102]. PCR fragments containing the two sgRNAs (See Additional file 4: Table S3 for primer sequences), along with the promoter and terminator sequences were generated from the $\mathrm{pCBC} \mathrm{DT} 1 \mathrm{~T} 2$ vector template using Phusion polymerase (ThermoFisher Scientific). The purified fragments containing the two sgRNAs were cloned into the final vector pBEE401E using a golden gate reaction with BsaI enzyme. This vector was modified to carry the Basta resistance marker (BlpR from pBUE411 [103]) rather than the original HygR marker in pHEE401E [36, 48]. Constructs were transformed into Agrobacteria by electroporation, which were then used to transform A. thaliana Col-0 by floral dip [101]. T1 seeds were cold stratified and sown on soil as previously described [26]. Once seedlings had germinated, selection for Basta $^{\mathrm{Tm}}$ herbicide resistance was carried out, and resistant seedlings were transplanted, and PCR screened for the Basta ${ }^{\mathrm{m}}$ selection marker and for genomic deletion. T1 plants were analyzed with primers pairs designed to amplify inside or outside of the deletion regions for BKN1/ $B K N 2$ to identify heterozygous mutants, and homozygous mutants carrying the respective gene deletions were identified in subsequent generations (T2-T5) for phenotyping. PCR products covering the deletions were sequenced to confirm the locations of each independent deletion mutation. For both $B K N s$, two constructs carrying different sgRNA target sites were 
screened for deletions in the T1 (Additional file 4: Table S3). The BKN1_CR \#1 and BKN1_CR \#3 constructs produced the $b k n 1-2$ and $b k n 1-3$ mutants, respectively. The BKN2_CR \#3 construct produced the $b k n 2-1$ and $b k n 2-2$ mutants. To generate double mutants, transgene free $b k n 1-3$ mutants were transformed with the $B K N 2 \_C R \# 2$ construct to produce three new bkn2 mutants, bkn2-3, bkn2-4 and bkn25 , in the bkn1-3 background.

To clone cDNAs for $A$. thaliana BKN2 (Col-0, At5g11410), A. lyrata BKN1 (AL6G22040.t1) and A. lyrata BKN2 (AL6G22050.t1), RT-PCR was conducted on RNA extracted from top $1 \frac{1}{2}$ pistil tissue. The $A$. thaliana $\mathrm{Hh}-0 B K N 1 \mathrm{cDNA}$ was cloned from stage 12 flower bud RNA. The $B K N$ clones were introduced into the TOPO entry clone using the PCR8/ GW TOPO cloning kit (ThermoFisher Scientific). To generate the Al-BKN2(G2A), Al-BKN2(C4A), and Al-BKN2(G2A, $\mathrm{C} 4 \mathrm{~A})$ constructs, the myristoylation (G2) and palmitoylation (C4) sites at the N-terminus of A. lyrata BKN2 were disrupted by PCR with primers to replace the G2 and C4 sites (Additional file 4: Table S3). Gateway reactions were carried out using LR clonase II enzyme (ThermoFisher) into the destination vector pEARLEYGATE 101 containing a C-terminal YFP (Earley et al., 2006). Plasmids were then transformed into Agrobacterium GV2260 by electroporation for the agroinfiltration experiments. Leaves 3 or 4 from 5 week-old $N$. benthamiana leaves were transformed by agroinfiltration as described in the protocol by Sparkes et al. [104].

\section{Promoter-GUS staining}

Inflorescences or stage 12 flowers from the $B K N 1$ and $B K N 2$ promoter-GUS transgenic plants were incubated in GUS solution overnight at $37^{\circ} \mathrm{C}$ according to the protocol used in Wang et al. [15]. Tissues were then fixed in ethanol:glacial acetic acid and cleared with chloral hydrate solution as described by [105]. Tissues were mounted in 30\% glycerol and images were taken on a Nikon sMz800 microscope.

\section{Confocal microscopy}

At 24 to $48 \mathrm{~h}$ post-infiltration, leaf disks were cut from $N$. benthamiana and visualized using a Leica TCS SP8 confocal microscope. Image processing was done using the Leica LAS AF lite software. Plasmolysis was achieved by treatment with $0.8 \mathrm{M}$ mannitol as described by Lang et al. [106]

\section{Expression profiling, multiple sequence alignments and phylogenetic analyses}

The BAR Expression Angler tool [39] (http://bar.utoronto.ca/) was used to search for stigma-enriched signalling proteins as previously described [36]. Briefly, the stigma-specific SLR1 gene as the bait (At3g12000, [40]) to search the AtGenExpress Plus-Extended Tissue Compendium dataset $[39,41]$. Expression profiling of the BKN genes for Additional file 1: Figure S1 came from three additional transcriptome datasets: the TRAVA RNA-Seq dataset (http://travadb.org/ [44]), the stigmatic papillae RNA-Seq dataset [43] and the stigma microarray datasets [35]; and the data was displayed using the HeatMapper Plus tool [39].

For ecotype polymorphism searches of the 1135 genomes [50], two different databases were used to retrieve the BKN1 genomic sequences: 1001 Genomes (https://1 001genomes.org/) and Salk Arabidopsis 1001 Genomes (http://signal.salk.edu/atg1001/index.php). Hh-0 was the first ecotype identified to carry the T128 and $\triangle \mathrm{A} 597$ to encode a full-length BKN1 protein. The MEGA7 software [63] was used to produce multiple protein sequence alignments of the BKN1 genomic sequences retrieved from the 1135 ecotype genomes. The Col-0 and Hh-0 BKN1 cDNA sequences were included to remove introns and locate the position of the two SNPs (Additional file 5 and Additional file 6). The two SNP regions were copied from the alignment into an excel file for further analysis (see Additional file 3: Table S2). Genomic DNA samples were used to PCR amplify and sequence the BKN1 gene for the Västervik, Dju-1 and Bela-1 ecotypes (Additional file 1: Figure S5).

For the phylogenetic analysis of Brassicaceae BKNs (Fig. 6), amino acid sequences (Additional file 7) were obtained from TAIR (A. thaliana) [49]; Phytozome (A. lyrata, B. oleracea capitata, B. stricta, E. salsugineum formerly T. halophila, C. rubella, C. grandiflora, C. papaya) [107]; NCBI (A. alpina, B. cretica, B. oleracea cv TO1000, T. hassleriana) [108]; EnsemblPlants (A. halleri, B. oleracea cv TO1000) [109]; BRAD (A. arabicum) [110]; or thellungiella.org (S. parvula - formerly T. parvula) servers using blastp or tblastn searches for genes similar to the BKNs or other RLCKs. For the phylogenetic analysis of Arabidopsis RLCK VII members (Additional file 1: Figure S8), the RLCK VII members defined by Lehti-Shiu and Shiu [51] were used, and amino acid sequences (Additional file 8) were retrieved from TAIR [49]. The MEGA7 software [63] was used to produce multiple protein sequence alignments using ClustalW [62]. The ClustalW alignments were trimmed at the $\mathrm{N}$-and $\mathrm{C}$-terminus and then used to generate a consensus tree by the Maximum Likelihood method [64] with 1000 bootstrap replicates [65] in MEGA7. Alignments in Additional file 1: Figure S3, S4, S5 and S6 were generated in MEGA7 and formatted with the Multiple Align Show tool (http://www.bioinformatics.org/sms/ [111]), using groupings of amino acids based on their side chains [112]. See additional files for all amino acid sequences and alignments.

\section{RT-PCR and quantitative RT-PCR software}

Anthers and pistil tissues (top-half: stigmas, bottom-half: ovaries) and were collected from stage 12 flower buds; 
leaves and roots were collected from 2-week-old A. thaliana seedlings for RT-PCR and quantitative RT-PCR applications. RNA was extracted using a modified protocol of the SV total RNA extraction kit (Promega) which included vigorous grinding of plant tissue in liquid nitrogen. Next, cDNA synthesis was carried out using Superscript III reverse transcriptase (ThermoFisher) and oligo dT primers. The cDNA was then used in RT-PCR reactions with Taq polymerase, and quantitative RT-PCR reactions with PowerUp 2x SYBR Green master mix (ThermoFisher) (primers listed in Additional file 4: Table S3).

\section{Assays for pollen hydration, pollen adhesion and pollen tube growth, and seed set}

Stage 12 flower buds were emasculated and carefully wrapped with plastic wrap and allowed to mature overnight. For pollen hydration, the next day, pistils were mounted upright in $1 / 2$ MS medium and hand-pollinated with a small amount of Col-0 pollen. Pictures were taken immediately at $0 \mathrm{~min}$ and again at $10 \mathrm{~min}$ post-pollination using a Nikon sMz800 microscope at 6x magnification with a $1.5 x$ objective. Pollen grain diameter was measured laterally using the Nikon digital imaging software for 10 random pollen grains per pistil, 3 pistils per genotype. All pollinations were performed under an ambient humidity lower than $60 \%$ to avoid spontaneous water uptake from the surrounding environment.

For pollen adhesion and pollen tube growth, the next day, pistils were carefully unwrapped and lightly pollinated with Col-0 pollen, or transgenic pollen for reciprocal crosses. At $2 \mathrm{~h}$ post-pollination, pistils were collected, fixed and stained with aniline blue to stain the callose deposited by pollen tubes, as described by Safavian et al. (2015). Pollinated pistils were imaged using a Zeiss Axioskop2Plus microscope under brightfield to count the number of pollen grains adhered, and under UV fluorescence to assess pollen tube growth. Pollen adhesion was quantified for $n=10$ pistils for each cross.

For seed set, late stage 12 buds were emasculated and hand-pollinated with Col-0 pollen for Col-0 pistils and for each transgenic line. Hand pollinations were marked with thread and siliques were allowed to mature fully over several days. Prior to senescence, green siliques were removed, and sliced longitudinally to count the number of developing seeds. 10 siliques were counted for each pollination.

\section{In vitro BKN2 Palmitoylation assay}

At-BKN2 and Al-BKN2 gateway entry clones were recombined into the Gateway destination vector pYESDEST52 (C-terminal V5 tagged, Invitrogen) to create yeast expression vectors pYES-Al-BKN2 and pYes-AtBKN2 respectively. Wild-type yeast BY4741 (MATa his $3 \Delta 1$ leu $2 \Delta 0$ met $15 \Delta 0$ ura $3 \Delta 0$ ) cells were transformed and grown at $25^{\circ} \mathrm{C}$ in selective minimal media minus uracil to select transgenic yeast cells. To induce protein expression, the transformed yeast cells were grown in minimal liquid media containing $2 \%$ galactose. The palmitoylation assay was carried out by the Acyl-RAC method $[82,113]$. Briefly, total proteins were lysed and recovered by acetone precipitation. Free $-\mathrm{SH}$ was blocked with $1 \%$ methyl methanethiosulfonate (MMTS), and samples were then treated with $1 \mathrm{M}$ hydroxylamine, $\mathrm{pH} 7.5\left(+\mathrm{NH}_{2} \mathrm{OH}\right)$ to remove palmitoylate and to expose free thiols at the palmitoylation sites. In the negative control $\left(-\mathrm{NH}_{2} \mathrm{OH}\right), 1 \mathrm{M}$ Tris $(\mathrm{pH} 7.5)$ was added. Palmitoylated proteins were captured on thiopropyl sepharose beads (Sigma), and the presence of BKN2 proteins were detected by ECL western blotting with antiV5 primary and HRP-conjugated secondary antibodies (CWBio, China).

\section{Supplementary information}

Supplementary information accompanies this paper at https://doi.org/10. 1186/s12870-019-2160-9.

\section{Additional file 1: Figure S1. Tissue expression profiles of the BKNs in different transcriptome datasets. Figure S2 Analysis of the bkn1-1 T-DNA mutant. Figure S3. Sequence Alignment of Arabidopsis BKN1 coding sequences. Figure S4. Arabidopsis genomic regions for the BKN genes and amino acid alignment for the BKN1 annotations. Figure S5. A. thaliana, A. lyrata and A. halleri amino acid alignments for BKN1, BKN2 and BKN3. Figure S6. Alignment of BKN1 coding sequences from four $A$. thaliana ecotypes. Figure S7. Pollen Hydration Assays in the Col-0 and Hh-0 ecotypes at 10 min post-pollination. Figure S8. Phylogenetic ana- lysis of the Arabidopsis RLCK subfamily VII members. Figure S9 Amino acid sequence alignment of BRASSIKIN (BKN) sequences with CASTAWAY (CST) sequences. Figure S10. Confocal microscopy imaging of $N$. benthamiana leaves infiltrated with C-terminal BKN:YFP fusion protein constructs and plasmolysed with $0.8 \mathrm{M}$ mannitol \\ Additional file 2: Table S1. BAR Expression Angler using the stigma specific SLR1 gene as a bait \\ Additional file 3: Table S2. Polymorphism searches across the 1001 genomes for At-BKN1 \\ Additional file $\mathbf{4}$ Table S3. Primers Used \\ Additional file 5. RLCK Amino acid sequences for Fig. 6 phylogenetic tree \\ Additional file 6. RLCK Amino acid sequences for Additional; file 1: Fig. S7 phylogenetic tree}

Additional file 7. RLCK Amino acid sequences for Fig. 6 phylogenetic tree Additional file 8. RLCK Amino acid sequences for Additional file 1: Fig. S7 phylogenetic tree

\section{Abbreviations}

BIK1: BOTRYTIS-INDUCED KINASE1; BKN: BRASSIKIN; CST: CASTAWAY; MMTS: Methyl methanethiosulfonate; MS: Murashige and Skoog; PBL: PBS1Like; PCP-B: Pollen Coat Protein-B; RLCK: Receptor-Like Cytoplasmic Kinase; SPIK: SHAKER POLLEN INWARD K+ channel

\section{Acknowledgements}

We thank Rebecca Hylton and Betty Geng for technical assistance, and members of the Goring lab for critically reading this review. Thanks also to the Yoshioka lab for providing the CAM4:YFP construct. We thank the Arabidopsis Biological Resource Center (ABRC) for providing seeds for the 
sequence-indexed Arabidopsis T-DNA insertion mutant and the Hh-0, Västervik, Dju-1 and Bela-1 ecotypes.

\section{Authors' contributions}

JD and DRG design the research; JD, HKL, NU, JX, and BQ performed the research; JD, DRG, HKL and $B Q$ conducted the data analysis; JD and DRG prepared the Figures and wrote the manuscript; JD, HKL, DRG and BQ edited the manuscript. All authors read and approved the final manuscript.

\section{Funding}

J.D. and H.K.L were supported by Ontario Graduate Scholarships (OGS). This research was supported by a grant from Natural Sciences and Engineering Research Council of Canada to D.R.G, and a grant from the Natural Science Foundation of China to B. Q. (grant number 31170233). The funders had no role in the design of the study and collection, analysis, and interpretation of data and in writing the manuscript.

\section{Availability of data and materials}

All data is included in this manuscript. Constructs and seeds are available upon request from the corresponding author.

\section{Ethics approval and consent to participate}

Not applicable.

\section{Consent for publication}

Not applicable.

\section{Competing interests}

The authors declare that they have no competing interests.

\section{Author details}

'Department of Cell \& Systems Biology, University of Toronto, Toronto M5S 3B2, Canada. ${ }^{2}$ School of Pharmacy \& Biomolecular Sciences, Liverpool John Moores University, Liverpool L3 3AF, UK. ${ }^{3}$ College of Horticulture, Agricultural University of Hebei, Baoding City 071001, Hebei Province, China. ${ }^{4}$ Centre for the Analysis of Genome Evolution \& Function, University of Toronto, Toronto M5S 3B2, Canada.

\section{Received: 4 June 2019 Accepted: 25 November 2019}

\section{Published online: 11 December 2019}

\section{References}

1. Dresselhaus T, Sprunck S, Wessel GM. Fertilization mechanisms in flowering plants. Curr Biol. 2016:26(3):R125-39.

2. Higashiyama T, Yang WC. Gametophytic pollen tube guidance: attractant peptides, Gametic controls, and receptors. Plant Physiol. 2017;173(1):112-21.

3. Chapman LA, Goring DR. Pollen-pistil interactions regulating successful fertilization in the Brassicaceae. J Exp Bot. 2010;61(7):1987-99.

4. Doucet J, Lee HK, Goring DR. Pollen acceptance or rejection: a tale of two pathways. Trends Plant Sci. 2016;21(12):1058-67.

5. Li H, Yang WC. RLKs orchestrate the signaling in plant male-female interaction. Sci China Life Sci. 2016;59(9):867-77.

6. Dickinson H. Dry stigmas, water and self-incompatibility in Brassica. Sex Plant Reprod. 1995;8(1):1-10.

7. Heslop-Harrison Y, Shivanna KR. The receptive surface of the angiosperm stigma. Ann Bot. 1977;41(6):1233-58.

8. Zinkl GM, Zwiebel Bl, Grier DG, Preuss D. Pollen-stigma adhesion in Arabidopsis: a species-specific interaction mediated by lipophilic molecules in the pollen exine. Development. 1999:126(23):5431-40.

9. Elleman CJ, Dickinson HG. The role of exine coating in pollen-stigma interactions in Brassica oleracea L. New Phytol. 1990;114(3):511-8.

10. Hiroi K, Sone M, Sakazono S, Osaka M, Masuko-Suzuki H, Matsuda T, Suzuki G, Suwabe K, Watanabe M. Time-lapse imaging of self- and crosspollinations in Brassica rapa. Ann Bot. 2013;112(1):115-22.

11. Ma J-F, Liu Z-H, Chu C-P, Hu Z-Y, Wang X-L, Zhang XS. Different regulatory processes control pollen hydration and germination in Arabidopsis. Sex Plant Reprod. 2012;25(1):77-82

12. Zuberi MI, Dickinson HG. Pollen-stigma interaction in Brassica. III. Hydration of the pollen grains. J Cell Sci. 1985;76:321-36.
13. Updegraff EP, Zhao F, Preuss D. The extracellular lipase EXL4 is required for efficient hydration of Arabidopsis pollen. Sex Plant Reprod. 2009; 22(3):197-204

14. Mayfield JA, Preuss D. Rapid initiation of Arabidopsis pollination requires the oleosin-domain protein GRP17. Nat Cell Biol. 2000;2(2):128-30.

15. Wang LD, Clarke LA, Eason RJ, Parker CC, Oi BX, Scott RJ, Doughty J. $\mathrm{PCP}-\mathrm{B}$ class pollen coat proteins are key regulators of the hydration checkpoint in Arabidopsis thaliana pollen-stigma interactions. New Phytol. 2017;213(2):764-77.

16. Jany $\mathrm{E}$, Nelles $\mathrm{H}$, Goring DR. The molecular and cellular regulation of Brassicaceae self-incompatibility and self-pollen rejection. Int Rev Cell Mol Biol. 2019;343:1-35.

17. Kaya H, Nakajima R, Iwano M, Kanaoka MM, Kimura S, Takeda S, Kawarazak T, Senzaki E, Hamamura Y, Higashiyama T, et al. Ca2+-activated reactive oxygen species production by Arabidopsis $\mathrm{RbohH}$ and $\mathrm{RbohJ}$ is essential for proper pollen tube tip growth. Plant Cell. 2014;26(3):1069-80.

18. Kaya H, Iwano M, Takeda S, Kanaoka MM, Kimura S, Abe M, Kuchitsu K Apoplastic ROS production upon pollination by RbohH and RbohJ in Arabidopsis. Plant Signal Behav. 2015;10(2):e989050.

19. Gao XQ, Liu CZ, Li DD, Zhao TT, Li F, Jia XN, Zhao XY, Zhang XS. The Arabidopsis KIN beta gamma subunit of the SnRK1 complex regulates pollen hydration on the stigma by mediating the level of reactive oxygen species in pollen. PLoS Genet. 2016;12(7):e1006228.

20. Li DD, Guan H, Li F, Liu CZ, Dong YX, Zhang XS, Gao XQ. Arabidopsis shaker pollen inward K+ channel SPIK functions in SnRK1 complex-regulated pollen hydration on the stigma. J Integr Plant Biol. 2017;59(9):604-11.

21. Indriolo E, Safavian D, Goring DR. The ARC1 E3 ligase promotes two different self-pollen avoidance traits in Arabidopsis. Plant Cell. 2014; 26(4):1525-43.

22. Safavian D, Goring DR. Secretory Activity Is Rapidly Induced in Stigmatic Papillae by Compatible Pollen, but Inhibited for Self-Incompatible Pollen in the Brassicaceae. PLoS One. 2013:8(12):e84286

23. Elleman CJ, Dickinson HG: Pollen-stigma interaction during sporophytic self-incompatibility in Brassica oleracea. In: Genetic control of self-incompatibility and reproductive development in flowering plants. Edited by Williams EG, Clarke AE, Knox RB. Dordrecht: Springer Netherlands; 1994: 67-87.

24. Elleman CJ, Dickinson HG. Identification of pollen components regulating pollination-specific responses in the stigmatic papillae of Brassica oleracea. New Phytol. 1996;133(2):197-205.

25. Iwano $M$, Shiba $H$, Matoba K, Miwa T, Funato M, Entani T, Nakayama $P$, Shimosato H, Takaoka A, Isogai A, et al. Actin dynamics in papilla cells of Brassica rapa during self- and cross-pollination. Plant Physiol. 2007; 144(1):72-81

26. Safavian D, Zayed $Y$, Indriolo E, Chapman L, Ahmed A, Goring DR. RNA silencing of exocyst genes in the stigma impairs the acceptance of compatible pollen in Arabidopsis. Plant Physiol. 2015:169(4):2526-38

27. Samuel MA, Chong YT, Haasen KE, Aldea-Brydges MG, Stone SL, Goring DR. Cellular pathways regulating responses to compatible and self-incompatible pollen in Brassica and Arabidopsis stigmas intersect at Exo70A1, a putative component of the exocyst complex. Plant Cell. 2009:21(9):2655-71.

28. Vukasinovic N, Zarsky V. Tethering complexes in the Arabidopsis endomembrane system. Front Cell Dev Biol. 2016:4:46.

29. Safavian D, Jamshed M, Sankaranarayanan S, Indriolo E, Samuel MA, Goring DR. High humidity partially rescues the Arabidopsis thaliana exo70A1 stigmatic defect for accepting compatible pollen. Plant Reproduction. 2014; 27(3):121-7.

30. Sankaranarayanan S, Jamshed M, Samuel MA. Degradation of glyoxalase I in Brassica napus stigma leads to self-incompatibility response. Nature Plants. 2015;1(12):15185.

31. Goring DR: Exocyst, exosomes, and autophagy in the regulation of Brassicaceae pollen-stigma interactions. J Exp Bot 2017, Sep 27.https://doi. org/10.1093/jxb/erx340. [Epub ahead of print].

32. Samuel MA, Tang $W$, Jamshed $M$, Northey J, Patel D, Smith D, Siu KWM, Muench DG, Wang Z-Y, Goring DR. Proteomic Analysis of Brassica Stigmatic Proteins Following the Self-incompatibility Reaction Reveals a Role for Microtubule Dynamics During Pollen Responses. Mol Cell Proteomics. 2011:10(12).

33. Scandola S, Samuel MA. A flower-specific phospholipase D is a stigmatic compatibility factor targeted by the self-incompatibility response in Brassica napus. Curr Biol. 2019 
34. Iwano M, Shiba H, Miwa T, Che FS, Takayama S, Nagai T, Miyawaki A, Isogai A. Ca2+ dynamics in a pollen grain and papilla cell during pollination of Arabidopsis. Plant Physiol. 2004;136(3):3562-71.

35. Iwano M, Igarashi $M$, Tarutani $Y$, Kaothien-Nakayama $P$, Nakayama $H$, Moriyama H, Yakabe R, Entani T, Shimosato-Asano H, Ueki M, et al. A pollen coat-inducible autoinhibited Ca2+-ATPase expressed in stigmatic papilla cells is required for compatible pollination in the Brassicaceae. Plant Cell. 2014;26(2):636-49.

36. Doucet J, Truong C, Frank-Webb E, Lee HK, Daneva A, Gao Z, Nowack M, Goring DR. Identification of a role for an E6-like 1 gene in early pollenstigma interactions in Arabidopsis thaliana. Plant Reprod. 2019.

37. Hulskamp M, Kopczak SD, Horejsi TF, Kihl BK, Pruitt RE. Identification of genes required for pollen-stigma recognition in Arabidopsis thaliana. Plant J. 1995:8(5):703-14

38. Luu DT, Passeleque E, Dumas C, Heizmann P. Pollen-stigma capture is not species discriminant within the Brassicaceae family. C R Acad Sci Ser III Sci Vie-Life Sci. 1998;321(9):747-55.

39. Toufighi K, Brady SM, Austin R, Ly E, Provart NJ. The botany Array resource: e-Northerns, expression angling, and promoter analyses. Plant J. 2005;43(1):153-63

40. Dwyer KG, Lalonde BA, Nasrallah JB, Nasrallah ME. Structure and expression of AtS1, an Arabidopsis thaliana gene homologous to the S-locus related genes of Brassica. Mol Gen Genet. 1992;231(3):442-8.

41. Schmid M, Davison TS, Henz SR, Pape UJ, Demar M, Vingron M, Scholkopf B, Weigel D, Lohmann JU. A gene expression map of Arabidopsis thaliana development. Nat Genet. 2005;37(5):501-6.

42. Swanson $R$, Clark T, Preuss D. Expression profiling of Arabidopsis stigma tissue identifies stigma-specific genes. Sex Plant Reprod. 2005; 18(4):163-71

43. Gao Z, Daneva A, Salanenka Y, Van Durme M, Huysmans M, Lin Z, De Winter F, Vanneste $S$, Karimi M, Van de Velde J, et al. KIRA1 and ORESARA1 terminate flower receptivity by promoting cell death in the stigma of Arabidopsis. Nat Plants. 2018;4(6):365-75.

44. Klepikova AV, Kasianov AS, Gerasimov ES, Logacheva MD, Penin AA. A high resolution map of the Arabidopsis thaliana developmental transcriptome based on RNA-seq profiling. Plant J. 2016;88(6):1058-70.

45. Krishnakumar V, Hanlon MR, Contrino S, Ferlanti ES, Karamycheva S, Kim M, Rosen BD, Cheng CY, Moreira W, Mock SA, et al. Araport: the Arabidopsis information portal. Nucleic Acids Res. 2015;43(Database issue):D1003-9.

46. Hammaren HM, Virtanen AT, Silvennoinen O. Nucleotide-binding mechanisms in pseudokinases. Biosci Rep. 2015;36(1):e00282.

47. Kwon A, Scott S, Taujale R, Yeung W, Kochut KJ, Eyers PA, Kannan N. Tracing the origin and evolution of pseudokinases across the tree of life. Sci Signal. 2019;12(578).

48. Wang $Z \mathrm{P}$, Xing $\mathrm{HL}$, Dong $\mathrm{L}$, Zhang $\mathrm{HY}$, Han $\mathrm{CY}$, Wang $X C$, Chen QJ. Egg cellspecific promoter-controlled CRISPR/Cas9 efficiently generates homozygous mutants for multiple target genes in Arabidopsis in a single generation. Genome Biol. 2015;16:144.

49. Berardini TZ, Reiser L, Li D, Mezheritsky Y, Muller R, Strait E, Huala E. The Arabidopsis information resource: making and mining the "gold standard" annotated reference plant genome. Genesis. 2015;53(8):474-85.

50. The 1001 Genomes Consortium. 1,135 genomes reveal the global pattern of polymorphism in Arabidopsis thaliana. Cell. 2016;166(2):481-91.

51. Lehti-Shiu MD, Shiu SH. Diversity, classification and function of the plant protein kinase superfamily. Philos Trans R Soc Lond Ser B Biol Sci. 2012; 367(1602):2619-39.

52. Veronese $\mathrm{P}$, Nakagami H, Bluhm B, Abuqamar S, Chen X, Salmeron J Dietrich RA, Hirt H, Mengiste T. The membrane-anchored BOTRYTISINDUCED KINASE1 plays distinct roles in Arabidopsis resistance to necrotrophic and biotrophic pathogens. Plant Cell. 2006;18(1):257-73.

53. Rao S, Zhou Z, Miao P, Bi G, Hu M, Wu Y, Feng F, Zhang X, Zhou JM. Roles of receptor-like cytoplasmic kinase VII members in pattern-triggered immune signaling. Plant Physiol. 2018;177(4):1679-90.

54. Zhang J, Li W, Xiang T, Liu Z, Laluk K, Ding X, Zou Y, Gao M, Zhang X, Chen $S$, et al. Receptor-like cytoplasmic kinases integrate signaling from multiple plant immune receptors and are targeted by a Pseudomonas syringae effector. Cell Host Microbe. 2010;7(4):290-301.

55. Burr CA, Leslie ME, Orlowski SK, Chen I, Wright CE, Daniels MJ, Liljegren SJ. CAST AWAY, a membrane-associated receptor-like kinase, inhibits organ abscission in Arabidopsis. Plant Physiol. 2011;156(4):1837-50.
56. Shiu SH, Bleecker AB. Plant receptor-like kinase gene family: diversity, function, and signaling. Sci STKE : Signal Transduction knowledge Environment. 2001;2001(113):re22.

57. Couto D, Zipfel C. Regulation of pattern recognition receptor signalling in plants. Nat Rev Immunol. 2016;16(9):537-52.

58. Gish LA, Clark SE. The RLK/Pelle family of kinases. Plant J. 2011;66(1):117-27.

59. Shiu SH, Bleecker AB. Receptor-like kinases from Arabidopsis form a monophyletic gene family related to animal receptor kinases. Proc Natl Acad Sci U S A. 2001;98(19):10763-8.

60. Murphy JM, Zhang Q, Young SN, Reese ML, Bailey FP, Eyers PA, Ungureanu $D$, Hammaren $H$, Silvennoinen $O$, Varghese $L N$, et al. A robust methodology to subclassify pseudokinases based on their nucleotide-binding properties. Biochem J. 2014:457(2):323-34

61. Koch MA, German DA. Taxonomy and systematics are key to biological information: Arabidopsis, Eutrema (Thellungiella), Noccaea and Schrenkiella (Brassicaceae) as examples. Front Plant Sci. 2013:4:267.

62. Larkin MA, Blackshields G, Brown NP, Chenna R, McGettigan PA, McWilliam H, Valentin F, Wallace IM, Wilm A, Lopez R, et al. Clustal W and Clustal X version 2.0. Bioinformatics. 2007;23(21):2947-8.

63. Kumar S, Stecher G, Tamura K. MEGA7: molecular evolutionary genetics analysis version 7.0 for bigger datasets. Mol Biol Evol. 2016;33(7):1870-4

64. Jones DT, Taylor WR, Thornton JM. The rapid generation of mutation data matrices from protein sequences. Comput Appl Biosci. 1992;8(3):275-82.

65. Felsenstein J. Confidence limits on phylogenies: an approach using the bootstrap. Evolution. 1985;39(4):783-91.

66. Sreeramulu S, Mostizky Y, Sunitha S, Shani E, Nahum H, Salomon D, Ben Hayun L, Gruetter C, Rauh D, Ori N, et al. BSKs are partially redundant positive regulators of brassinosteroid signaling in Arabidopsis. Plant J. 2013; 74(6):905-19.

67. Ren H, Willige BC, Jaillais Y, Geng S, Park MY, Gray WM, Chory J. BRASSINOSTEROID-SIGNALING KINASE 3, a plasma membrane-associated scaffold protein involved in early brassinosteroid signaling. PLoS Genet. 2019;15(1):e1007904

68. Nimchuk ZL, Tarr PT, Meyerowitz EM. An evolutionarily conserved pseudokinase mediates stem cell production in plants. Plant Cell. 2011; 23(3):851-4.

69. Somssich M, Bleckmann A, Simon R. Shared and distinct functions of the pseudokinase CORYNE (CRN) in shoot and root stem cell maintenance of Arabidopsis. J Exp Bot. 2016;67(16):4901-15.

70. Halter T, Imkampe J, Mazzotta S, Wierzba M, Postel S, Bucherl C, Kiefer C, Stahl M, Chinchilla D, Wang $X$, et al. The leucine-rich repeat receptor kinase BIR2 is a negative regulator of BAK1 in plant immunity. Curr Biol. 2014;24(2):134-43.

71. Chevalier D, Batoux M, Fulton L, Pfister K, Yadav RK, Schellenberg M, Schneitz K. STRUBBELIG defines a receptor kinase-mediated signaling pathway regulating organ development in Arabidopsis. Proc Natl Acad Sci U S A. 2005:102(25):9074-9.

72. Vaddepalli P, Herrmann A, Fulton L, Oelschner M, Hillmer S, Stratil TF, Fastner A, Hammes UZ, Ott T, Robinson DG, et al. The C2-domain protein QUIRKY and the receptor-like kinase STRUBBELIG localize to plasmodesmata and mediate tissue morphogenesis in Arabidopsis thaliana. Development. 2014;141(21):4139-48.

73. Sierla M, Horak H, Overmyer K, Waszczak C, Yarmolinsky D, Maierhofer T, Vainonen JP, Salojarvi J, Denessiouk K, Laanemets K, et al. The receptor-like Pseudokinase GHR1 is required for Stomatal closure. Plant Cell. 2018;30(11):2813-37.

74. Kumar D, Kumar R, Baek D, Hyun TK, Chung WS, Yun DJ, Kim JY. Arabidopsis thaliana RECEPTOR DEAD KINASE1 functions as a positive regulator in plant responses to ABA. Mol Plant. 2017:10(2):223-43.

75. Hemsley P, Taylor L, Grierson C. Palmitoylation affects multiple processes in Arabidopsis. Comp Biochem Physiol Mol Integr Physiol. 2008;150(3):S143-3.

76. Boyle PC, Martin GB. Greasy tactics in the plant-pathogen molecular arms race. J Exp Bot. 2015;66(6):1607-16.

77. Li Y, Qi B. Progress toward understanding protein S-acylation: prospective in plants. Front Plant Sci. 2017:8:346

78. Yamauchi S, Fusada N, Hayashi H, Utsumi T, Uozumi N, Endo Y, Tozawa Y. The consensus motif for $\mathrm{N}$-myristoylation of plant proteins in a wheat germ cell-free translation system. FEBS J. 2010;277(17):3596-607.

79. Earley KW, Haag JR, Pontes O, Opper K, Juehne T, Song KM, Pikaard CS. Gateway-compatible vectors for plant functional genomics and proteomics. Plant J. 2006;45(4):616-29. 
80. Cheng X, Lang I, Adeniji OS, Griffing L. Plasmolysis-deplasmolysis causes changes in endoplasmic reticulum form, movement, flow, and cytoskeletal association. J Exp Bot. 2017;68(15):4075-87.

81. Hemsley PA. The importance of lipid modified proteins in plants. New Phytol. 2015;205(2):476-89.

82. Forrester MT, Hess DT, Thompson JW, Hultman R, Moseley MA, Stamler JS, Casey PJ. Site-specific analysis of protein S-acylation by resin-assisted capture. J Lipid Res. 2011;52(2):393-8.

83. Castells $\mathrm{E}$, Casacuberta JM. Signalling through kinase-defective domains: the prevalence of atypical receptor-like kinases in plants. J Exp Bot. 2007;58(13):3503-11.

84. Lewis JD, Lee AH, Hassan JA, Wan J, Hurley B, Jhingree JR, Wang PW, Lo T, Youn JY, Guttman DS, et al. The Arabidopsis ZED1 pseudokinase is required for ZAR1-mediated immunity induced by the Pseudomonas syringae type III effector HopZ1a. Proc Natl Acad Sci U S A. 2013;110(46):18722-7.

85. Lewis JD, Lo T, Bastedo P, Guttman DS, Desveaux D. The rise of the undead: pseudokinases as mediators of effector-triggered immunity. Plant Signal Behav. 2014;9(1):e27563.

86. Tang WQ, Kim TW, Oses-Prieto JA, Sun Y, Deng ZP, Zhu SW, Wang RJ, Burlingame AL, Wang ZY. BSKs mediate signal transduction from the receptor kinase BRI1 in Arabidopsis. Science. 2008;321(5888):557-60.

87. Kim TW, Wang ZY. Brassinosteroid signal transduction from receptor kinases to transcription factors. Annu Rev Plant Biol. 2010;61:681-704.

88. Bleckmann A, Weidtkamp-Peters S, Seidel CA, Simon R. Stem cell signaling in Arabidopsis requires CRN to localize CLV2 to the plasma membrane. Plant Physiol. 2010;152(1):166-76.

89. Hu C, Zhu Y, Cui Y, Cheng K, Liang W, Wei Z, Zhu M, Yin H, Zeng L, Xiao Y, et al. A group of receptor kinases are essential for CLAVATA signalling to maintain stem cell homeostasis. Nat Plants. 2018;4(4):205-11.

90. Wang J, Wang J, Hu M, Wu S, Qi J, Wang G, Han Z, Qi Y, Gao N, Wang HW, et al. Ligand-triggered allosteric ADP release primes a plant NLR complex. Science. 2019;364(6435).

91. Liu C, Cui D, Zhao J, Liu N, Wang B, Liu J, Xu E, Hu Z, Ren D, Tang D, Hu Y. Two Arabidopsis receptor-like cytoplasmic kinases SZE1 and SZE2 associate with the ZAR1-ZED1 complex and are required for effector-triggered immunity. Mol Plant. 2019;12(7):967-83.

92. Vekemans X, Poux C, Goubet PM, Castric V. The evolution of selfing from outcrossing ancestors in Brassicaceae: what have we learned from variation at the S-locus? J Evol Biol. 2014;27(7):1372-85

93. Shimizu KK, Tsuchimatsu T. Evolution of Selfing: recurrent patterns in molecular adaptation. Annu Rev Ecol Evol Syst. 2015;46(1):593-622.

94. Luo Y, Widmer A. Herkogamy and its effects on mating patterns in Arabidopsis thaliana. PLoS One. 2013;8(2):e57902.

95. Sicard A, Lenhard M. The selfing syndrome: a model for studying the genetic and evolutionary basis of morphological adaptation in plants. Ann Bot. 2011;107(9):1433-43

96. Torang P, Vikstrom L, Wunder J, Wotzel S, Coupland G, Agren J. Evolution of the selfing syndrome: anther orientation and herkogamy together determine reproductive assurance in a self-compatible plant. Evolution. 2017:71(9):2206-18.

97. Mable BK, Robertson AV, Dart S, Di Berardo C, Witham L. Breakdown of selfincompatibility in the perennial Arabidopsis lyrata (Brassicaceae) and its genetic consequences. Evolution. 2005;59(7):1437-48.

98. Carleial S, van Kleunen M, Stift M. Small reductions in corolla size and pollen: ovule ratio, but no changes in flower shape in selfing populations of the north American Arabidopsis lyrata. Oecologia. 2017:183(2):401-13.

99. Mable BK, Hagmann J, Kim ST, Adam A, Kilbride E, Weigel D, Stift M. What causes mating system shifts in plants? Arabidopsis lyrata as a case study. Heredity (Edinb). 2017;118(1):52-63.

100. Coutu C, Brandle J, Brown D, Brown K, Miki B, Simmonds J, Hegedus DD PORE: a Modular binary vector series suited for both monocot and dicot plant transformation. Transgenic Res. 2007;16(6):771-81.

101. Clough SJ, Bent AF. Floral dip: a simplified method for agrobacteriummediated transformation of Arabidopsis thaliana. Plant J. 1998;16(6):735-43.

102. Labun K, Montague TG, Gagnon JA, Thyme SB, Valen E. CHOPCHOP v2: a web tool for the next generation of CRISPR genome engineering. Nucleic Acids Res. 2016:44(W1):W272-6.

103. Xing HL, Dong L, Wang ZP, Zhang HY, Han CY, Liu B, Wang XC, Chen QJ. A CRISPR Cas9 toolkit for multiplex genome editing in plants. BMC Plant Biol. 2014;14:327.

104. Sparkes IA, Runions J, Kearns A, Hawes C. Rapid, transient expression of fluorescent fusion proteins in tobacco plants and generation of stably transformed plants. Nat Protoc. 2006;1(4):2019-25.
105. Berleth $T$, Jurgens $G$. The role of the Monopteros gene in organizing the basal body region of the Arabidopsis embryo. Development. 1993;118(2):575-87.

106. Lang I, Sassmann S, Schmidt B, Komis G. Plasmolysis: loss of turgor and beyond. Plants (Basel). 2014;3(4):583-93.

107. Goodstein DM, Shu S, Howson R, Neupane R, Hayes RD, Fazo J, Mitros T, Dirks W, Hellsten U, Putnam N, et al. Phytozome: a comparative platform for green plant genomics. Nucleic Acids Res. 2012;40(Database Issue):D1178-86.

108. Coordinators NR. Database resources of the National Center for biotechnology information. Nucleic Acids Res. 2017;45(D1):D12-7.

109. Kersey PJ, Allen JE, Allot A, Barba M, Boddu S, Bolt BJ, Carvalho-Silva D, Christensen M, Davis P, Grabmueller C, et al. Ensembl genomes 2018: an integrated omics infrastructure for non-vertebrate species. Nucleic Acids Res. 2018;46(D1):D802-8.

110. Wang X, Wu J, Liang J, Cheng F, Wang X. Brassica database (BRAD) version 2.0: integrating and mining Brassicaceae species genomic resources. Database (Oxford). 2015;2015.

111. Stothard $P$. The sequence manipulation suite: JavaScript programs for analyzing and formatting protein and DNA sequences. Biotechniques. 2000; 28(6):1102 1104

112. Das JK, Das P, Ray KK, Choudhury PP, Jana SS. Mathematical characterization of protein sequences using patterns as chemical group combinations of amino acids. PLoS One. 2016;11(12):e0167651.

113. Li Y, Scott R, Doughty J, Grant M, Qi B. Protein S-Acyltransferase 14: a specific role for Palmitoylation in leaf senescence in Arabidopsis. Plant Physiol. 2016;170(1):415-28.

\section{Publisher's Note}

Springer Nature remains neutral with regard to jurisdictional claims in published maps and institutional affiliations.

Ready to submit your research? Choose BMC and benefit from:

- fast, convenient online submission

- thorough peer review by experienced researchers in your field

- rapid publication on acceptance

- support for research data, including large and complex data types

- gold Open Access which fosters wider collaboration and increased citations

- maximum visibility for your research: over $100 \mathrm{M}$ website views per year

At $\mathrm{BMC}$, research is always in progress.

Learn more biomedcentral.com/submissions 